\title{
Integrated ionomic and transcriptomic dissection reveals the core transporter genes responsive to varying cadmium abundances in allotetraploid rapeseed
}

Ting Zhou', Cai-peng Yue ${ }^{\dagger}$, Tian-yu Zhang, Ying Liu, Jin-yong Huang and Ying-peng Hua*

\begin{abstract}
Background: Oilseed rape (B. napus L.) has great potential for phytoremediation of cadmium (Cd)-polluted soils due to its large plant biomass production and strong metal accumulation. Soil properties and the presence of other soluble compounds or ions, cause a heterogeneous distribution of $\mathrm{Cd}$.

Results: The aim of our study was to reveal the differential responses of $B$. napus to different $\mathrm{Cd}$ abundances. Herein, we found that high $\mathrm{Cd}(50 \mu \mathrm{M})$ severely inhibited the growth of $B$. napus, which was not repressed by low $\mathrm{Cd}(0.50 \mu \mathrm{M})$ under hydroponic culture system. ICP-MS assays showed that the $\mathrm{Cd}^{2+}$ concentrations in both shoots and roots under $50 \mu \mathrm{M} \mathrm{Cd}$ were over 10 times higher than those under $0.50 \mu \mathrm{M} C \mathrm{Cd}$. Under low $\mathrm{Cd}$, the concentrations of only shoot $\mathrm{Ca}^{2+} / \mathrm{Mn}^{2+}$ and root $\mathrm{Mn}^{2+}$ were obviously changed (both reduced); under high $\mathrm{Cd}$, the concentrations of most cations assayed were significantly altered in both shoots and roots except root $\mathrm{Ca}^{2+}$ and $\mathrm{Mg}^{2+}$. High-throughput transcriptomic profiling revealed a total of 18,021 and 1408 differentially expressed genes under high $\mathrm{Cd}$ and low $\mathrm{Cd}$ conditions, respectively. The biological categories related to the biosynthesis of plant cell wall components and response to external stimulus were over-accumulated under low $\mathrm{Cd}$, whereas the terms involving photosynthesis, nitrogen transport and response, and cellular metal ion homeostasis were highly enriched under high $\mathrm{Cd}$. Differential expression of the transporters responsible for $\mathrm{Cd}$ uptake (NRAMPs), transport (IRTs and ZIPS), sequestration (HMAs, ABCS, and CAXs), and detoxification (MTPS, PCR, MTs, and PCSs), and some other essential nutrient transporters were investigated, and gene co-expression network analysis revealed the core members of these $\mathrm{Cd}$ transporters. Some $\mathrm{Cd}$ transporter genes, especially NRAMPs and IRTs, showed opposite responsive patterns between high $\mathrm{Cd}$ and low $\mathrm{Cd}$ conditions.
\end{abstract}

Conclusions: Our findings would enrich our understanding of the interaction between essential nutrients and $\mathrm{Cd}$, and might also provide suitable gene resources and important implications for the genetic improvement of plant $\mathrm{Cd}$ accumulation and resistance through molecular engineering of these core genes under varying $\mathrm{Cd}$ abundances in soils.

Keywords: B. napus, Core transporters, lonome, Transcriptome, Varying cadmium abundances

\footnotetext{
*Correspondence: yingpenghua@zzu.edu.cn

${ }^{\dagger}$ Ting Zhou and Cai-peng Yue contributed equally to this work.

School of Agricultural Sciences, Zhengzhou University, Zhengzhou 450001,

China
}

(C) The Author(s). 2021 Open Access This article is licensed under a Creative Commons Attribution 4.0 International License, which permits use, sharing, adaptation, distribution and reproduction in any medium or format, as long as you give appropriate credit to the original author(s) and the source, provide a link to the Creative Commons licence, and indicate if changes were made. The images or other third party material in this article are included in the article's Creative Commons licence, unless indicated otherwise in a credit line to the material. If material is not included in the article's Creative Commons licence and your intended use is not permitted by statutory regulation or exceeds the permitted use, you will need to obtain permission directly from the copyright holder. To view a copy of this licence, visit http://creativecommons.org/licenses/by/4.0/ The Creative Commons Public Domain Dedication waiver (http://creativecommons.org/publicdomain/zero/1.0/) applies to the data made available in this article, unless otherwise stated in a credit line to the data. 


\section{Background}

Cadmium $(\mathrm{Cd})$ is a non-essential heavy metal with high biotoxicity for many living organism [1]. Cd has been identified to occur in large quantities of arable land worldwide, and its hyperaccumulation in the edible parts of agricultural crops is causing serious health threat to human beings and animals [2]. Geologically weathering of rocks is a major natural source of Cd contaminants, while the primary anthropogenic sources of $\mathrm{Cd}$, including agrochemicals, manufacturing, vehicular emission, irrigation wastewater, smelting, and mining also resulted in severe Cd pollution [3].

Accumulation of $\mathrm{Cd}$ in plants is regulated by several processes, including root adsorption, cell wall retention, xylem loading, vacuolar sequestration, and efflux [4]. When present in ionic form, Cd transport from root to other tissues is mainly mediated by three types of transporters, such as low-affinity calcium (Ca) transporters (LCTs), ZIP [(zinc transporter proteins (ZRT)- and ironregulated transporter (IRT)-like protein)] transporters, and natural resistance-associated macrophage proteins (NRAMPs) [4]. OsLCT1 localized at the plasma membrane shows $\mathrm{Cd}$ efflux activity in yeast, and functions at the nodes in Cd transport into grains [5]. OsNRAMP5, a major influx transporter for $\mathrm{Cd}$, is localized at the distal side of the root epidermis cells [6, 7]. SnYSL3, a member of the Yellow Stripe-Like (YSL) transporters, encodes a plasma-localized transporter delivering $\mathrm{Cd}$ nicotianamine complexes in Solanum nigrum [8]. Some $\mathrm{Fe}^{2+}$ transporters, such as OsIRT1, OsIRT2, and OsNRAMP1, are potentially involved in Cd uptake $[9,10]$, whereas they contribute to a small part of Cd uptake.

After entering the roots, a part of $\mathrm{Cd}$ is sequestered into root vacuoles by the tonoplast-localized heavy metal ATPase, OsHMA3 [11]. The OsHMA2 transporter is involved in the root-to-shoot translocation of $\mathrm{Cd}$ in rice [12]. The cation exchangers (CAX), AtCAX2, and AtCAX4, also transport $\mathrm{Cd}$ into vacuoles [13]. In addition to binding to nicotianamine, $\mathrm{Cd}$ can also bind with phytochelatins (PCs) that are cysteine-rich polypeptides, which are enzymatically synthesized by the $\gamma$ glutamyl-cysteine dipeptide transpeptidase (PC synthase, PCS) [14]. The Cd-PCs complexes formed in the cytosol are transferred to vacuoles by the tonoplast-localized ATP-binding cassette (ABC) transporters, including $\mathrm{ABCC} 1, \mathrm{ABCC} 2$, and $\mathrm{ABCC} 3[15,16]$. OsABCG36 is reported to be essential for $\mathrm{Cd}$ tolerance by exporting $\mathrm{Cd}$ or $\mathrm{Cd}$ conjugates from rice root cells [17]. Metallothioneins (MTs), also belonging to cysteine-rich protein family members, help plants to store high concentrations of $\mathrm{Cd}$ by binding with $\mathrm{Cd}$ [4]. Cystein-rich membrane proteins, named as plant $\mathrm{Cd}$ resistance (PCR), reduce metal content in plants through increasing heavy metal efflux [18]. The metal tolerance proteins (MTPs), also designated as cation diffusion facilitators (CDFs), are necessary for $\mathrm{Cd}$ sequestration or efflux in diverse plants [19]. In addition, exogenous bioactive substances, such as melatonin and glutathione, usually have an obvious effect on $\mathrm{Cd}$ accumulation and $\mathrm{Cd}$ toxicity resistance [20, 21].

Phytoremediation has been considered as an environmentally friendly and cost-effective approach for removing toxic metals, including $\mathrm{Cd}$, from polluted soils [4]. Previous studies have identified a number of model plants as heavy metal hyperaccumulators, such as Sedum plumbizincicola, Arabidopsis helleri, and Noccaea caerulescens $[22,23]$. However, whilst these plant species have strong metal accumulation, they only produce relatively low biomass. This limitation seriously restricts their practical use in the phytoremediation of heavy metal pollutants in the ecosystems.

Soil properties, including the total and available concentration of $\mathrm{Cd}, \mathrm{pH}$ and organic matter content, cation exchange capacity, clay content, and the presence of other soluble compounds or ions, cause a heterogeneous distribution of $\mathrm{Cd}$, which further lead to distinct responses of plants to varying $\mathrm{Cd}$ abundances [24]. High $\mathrm{Cd}$ concentrations, but not low $\mathrm{Cd}$, cause severe toxicity symptoms and significantly inhibit plant growth [2]. However, long-term exposure to low $\mathrm{Cd}$ concentrations poses a potential threat to human health and plant growth [25].

Allotetraploid rapeseed (B. napus L., $\mathrm{A}_{n} \mathrm{~A}_{n} \mathrm{C}_{n} \mathrm{C}_{n}$, $1130 \mathrm{Mb}, 2 \mathrm{n}=4 \mathrm{x}=38$ ) originated from spontaneous interspecific hybridization between the diploid progenitors B. rapa $\left(\mathrm{A}_{\mathrm{r}} \mathrm{A}_{\mathrm{r}}, \sim 485 \mathrm{Mb}, 2 \mathrm{n}=2 \mathrm{x}=20\right)$ and $B$. oleracea $\left(\mathrm{C}_{\mathrm{o}} \mathrm{C}_{\mathrm{o}}, \sim 630 \mathrm{Mb}, 2 \mathrm{n}=2 \mathrm{x}=18\right)$ about 7500 years ago, followed by chromosome doubling, a process known as allopolyploidy [26]. In addition to being a major vegetable oil source worldwide, oilseed rape shows great potential for phytoremediation by virtue of its large biomass production and strong metal accumulation [27, 28]. Previous studies, focusing on the responses of $B$. napus and other plant species under a certain $\mathrm{Cd}$ concentration [29, 30], lack systematic comparative analysis of the molecular responses of plants to both high $\mathrm{Cd}$ and low $\mathrm{Cd}$ abundances.

Taken together, in this study, we were aimed to investigate the differential ionomic and genome-wide transcriptional responses of allotetraploid rapeseed $\left(\mathrm{A}_{\mathrm{n}} \mathrm{A}_{\mathrm{n}} \mathrm{C}_{\mathrm{n}} \mathrm{C}_{\mathrm{n}}\right)$ to varying $\mathrm{Cd}$ abundances, and further identify the core $\mathrm{Cd}$ transporter gene members responsive to high $\mathrm{Cd}$ and low $\mathrm{Cd}$ based on the gene coexpression network analysis. The differential expression of $\mathrm{Cd}$ transporter genes under high $\mathrm{Cd}$ and low $\mathrm{Cd}$ conditions might be used to assess the soil $\mathrm{Cd}$ abundances. Moreover, our findings would provide suitable gene resources and important implications for the genetic 
improvement of plant $\mathrm{Cd}$ accumulation and resistance through molecular engineering of these genes under varying $\mathrm{Cd}$ abundances in soils.

\section{Results}

Differential ionomic responses of $B$. napus to high $\mathrm{cd}$ and low cd abundances

In order to assess the responses of B. napus to high $\mathrm{Cd}$ and low $\mathrm{Cd}$ conditions, the plants were grown under a hydroponic culture system. Under low $\mathrm{Cd}$, the rapeseed plants did not show obvious growth defects in both shoots and roots. However, under high $\mathrm{Cd}$, remarkable leaf chlorosis and root inhibition was observed (Fig. 1A, B), which was indicated by smaller SPAD (soil and plant analyzer development) and root length values (Fig. 1C, D). In addition, high $\mathrm{Cd}$ also reduced the biomasses in both shoots and roots, which was not significantly changed under low Cd (Fig. 1E, F). Compared with the control $(0.28 \pm 0.05)$, high $\mathrm{Cd}(0.46 \pm 0.11)$ caused an significant increase in the root/shoot ratio, which was not obviously changed under low $\mathrm{Cd}(0.25 \pm 0.04)$.

Subsequently, the ICP-MS was used to assay the ionomic profiling of several mineral cations, including $\mathrm{Cd}^{2+}$, potassium $\left(\mathrm{K}^{+}\right)$, calcium $\left(\mathrm{Ca}^{2+}\right)$, magnesium $\left(\mathrm{Mg}^{2+}\right)$, iron $\left(\mathrm{Fe}^{2+}\right)$, zinc $\left(\mathrm{Zn}^{2+}\right)$, manganese $\left(\mathrm{Mn}^{2+}\right)$, copper $\left(\mathrm{Cu}^{2+}\right)$, and sodium $\left(\mathrm{Na}^{+}\right)$, between high $\mathrm{Cd}$ and low $\mathrm{Cd}$ abundances. Under both low $\mathrm{Cd}$ and high $\mathrm{Cd}$ conditions, much higher $\mathrm{Cd}^{2+}$ concentrations were observed in the roots than in the shoots (Fig. 1G). Although the $\mathrm{Cd}^{2+}$ concentration $(50 \mu \mathrm{M})$ in the solution under high Cd were 100 fold of that $(0.5 \mu \mathrm{M})$ under low $\mathrm{Cd}$, the $\mathrm{Cd}^{2+}$ concentrations in both shoots and roots under high $\mathrm{Cd}$ were over 10 times higher than those under low $\mathrm{Cd}$ (Fig. 1G).

In general, according to the responsive patterns of the other eight cations, we divided them into five groups: (i) $\mathrm{K}^{+}$, (ii) $\mathrm{Ca}^{2+}$ and $\mathrm{Mg}^{2+}$, (iii) $\mathrm{Fe}^{2+}, \mathrm{Zn}^{2+}$, and $\mathrm{Cu}^{2+}$, (iv) $\mathrm{Mn}^{2+}$, and (v) $\mathrm{Na}^{+}$(Fig. $1 \mathrm{H}-\mathrm{O}$ ). The $\mathrm{K}^{+}$concentrations were not significantly changed in both shoots and roots under low $\mathrm{Cd}$, whereas its concentrations were reduced by 15.41 and $70.06 \%$ in the shoots and roots, respectively, under high $\mathrm{Cd}$ (Fig. $1 \mathrm{H}$ ). In terms of both $\mathrm{Ca}^{2+}$ and $\mathrm{Mg}^{2+}$, we observed their decreased concentrations under low $\mathrm{Cd}$ but increased concentrations in the shoots under high $\mathrm{Cd}$, whereas no significant changes were found in the roots (Fig. 1I, J). All the concentrations of $\mathrm{Fe}^{2+}, \mathrm{Zn}^{2+}$, and $\mathrm{Cu}^{2+}$ were not significantly changed in both shoots and roots under low $\mathrm{Cd}$, whereas their concentrations were significantly reduced in the shoots but were increased in the roots under high $\mathrm{Cd}$ (Fig. 1K-M). In the shoots, the $\mathrm{Mn}^{2+}$ concentrations were reduced by 32.22 and $16.99 \%$ under high $\mathrm{Cd}$ and low $\mathrm{Cd}$ conditions, respectively (Fig. $1 \mathrm{~N})$. In the roots, the $\mathrm{Mn}^{2+}$ concentrations were decreased by 85.47 and $33.01 \%$ under high
$\mathrm{Cd}$ and low $\mathrm{Cd}$ conditions, respectively (Fig. $1 \mathrm{~N}$ ). The $\mathrm{Na}^{+}$concentrations were not significantly changed in both shoots and roots under low $\mathrm{Cd}$. However, under high $\mathrm{Cd}$, the $\mathrm{Na}^{+}$concentration was significantly increased in the shoots whereas was decreased by $46.15 \%$ in the roots (Fig. 1O).

\section{Overview of the high-throughput transcriptome sequencing data}

To investigate the genome-wide transcriptomic responses to high $\mathrm{Cd}$ and low $\mathrm{Cd}$ conditions, an Illumina HiSeq 4000 system (read length $150 \mathrm{bp}$, paired end) was used to perform an analysis of high-throughput transcriptional profiling on B. napus. After removal of adaptor sequences and low-quality reads, on average, more than $4.7 \times 10^{7}$ clean reads were obtained for each sample, and the total length of clean reads reached $1.2 \times$ $10^{9} \mathrm{nt}$ with the base-calling accuracy of more than $97 \%$ $\mathrm{Q}_{20}$ and $93 \% \mathrm{Q}_{30}$ (Supplementary Table S1). In general, all the GC content of 18 RNA samples of rapeseed plants were about $47 \%$ in this study. For each sample, $\sim 90 \%$ of the clean reads was mapped to the B. napus reference transcriptome sequence.

In this study, a total of 10 DEGs, including a senescence associated gene (SAG) BnaA6.SAG12, a boron channel gene nodulin 26-like intrinsic protein 6;1 (BnaA2.NIP6;1), BnaA9.PCR2, BnaC7.NRAMP4, BnaA7.ABCG36, a gene encoding a reactive oxygen species-producing protein $B n a C 2 . R B O H D$, BnaCn.ABCC3, two nitrate transporter (NRT) genes (BnaC5.NRT1.5 and BnaA9.NRTT1.1), and BnaC1.HMA3, were selected to compare their expression correlation between the RT-qPCR assays and transcriptome sequencing. The results showed that the gene expression was highly correlated $\left(R^{2}>0.96\right)$ between the two assays (Fig. 2A, B). Based on the normalized expression results between two biological replicates, Pearson correlation coefficients were calculated, most of which were more than 0.95 (Fig. 2C) between each pair of biological replicates under different $\mathrm{Cd}$ treatments. Clustering trees, presenting the distances among biological replicates, showed similar heights among the three biological replicates of each sample. The hierarchical clustering of genome-wide gene expression revealed that a similar expression pattern existed in the three biological replicates of each sample. Taken together, both the analyses of correlation and clustering indicated that the transcriptome sequencing data were of high quality among different biological replicates.

\section{Genome-scale transcriptomic responses of B. napus to high cd and low cd conditions}

To investigate the differential molecular responses of $B$. napus to varying $\mathrm{Cd}$ abundances, this study was aimed 

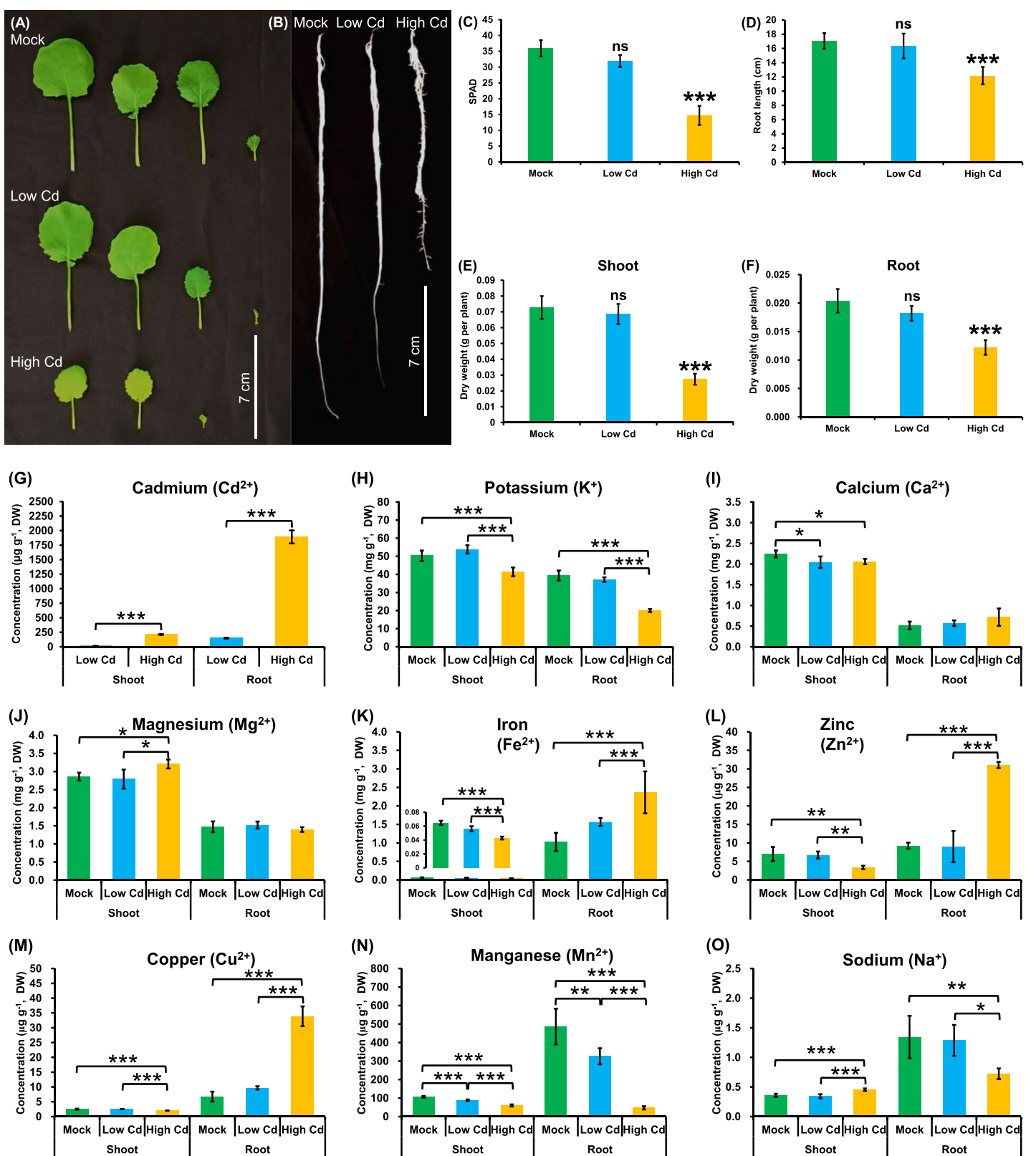

Fig. 1 Comparative analysis of growth performance and ion concentrations in rapeseed plants under varying Cd abundances. (A-B) Shoot (A) and root (B) growth performance, (C) leaf SPAD values, (D) root length, and (E-F) shoot $(\mathbf{E})$ and root $(\mathbf{F})$ dry weight of rapeseed plants under high $\mathrm{Cd}$ and low Cd conditions. (G-P) The concentrations of $\mathrm{Cd}^{2+}(\mathbf{G}), \mathrm{K}^{+}(\mathbf{H}), \mathrm{Ca}^{2+}(\mathbf{I}), \mathrm{Mg}^{2+}(\mathbf{J}), \mathrm{Fe}^{2+}(\mathbf{K}), \mathrm{Zn}^{2+}(\mathbf{L}), \mathrm{Cu}^{2+}(\mathbf{M}), \mathrm{Mn}^{2+}(\mathbf{N})$, and $\mathrm{Na}^{+}(\mathbf{O})$ in rapeseed plants under high $\mathrm{Cd}$ and low $\mathrm{Cd}$ conditions. Uniform rapeseed plants after 7-day seed germination were grown for $10 \mathrm{~d}$ under $\mathrm{Cd}$-free condition, and then the seedlings were transferred to the solution containing $C d$-free $(0 \mu \mathrm{M})$, low $\mathrm{Cd}(0.50 \mu \mathrm{M})$, and high $\mathrm{Cd}\left(50 \mu \mathrm{M} C \mathrm{Cl} \mathrm{I}_{2}\right)$ for 5 days until sampling. Mock means the Cd-free condition; ns, not significant. ${ }^{*}, P<0.05 ;{ }^{* *}, P<0.01{ }^{* * *}, P<0.001$

to identify the global differential expression profiling under high $\mathrm{Cd}$ and low $\mathrm{Cd}$ conditions. In both shoots and roots, different $\mathrm{Cd}$ abundances exhibited significantly differential transcriptomic features (Fig. 2D), indicating $\mathrm{Cd}$ abundances-dependent transcriptional responses to $\mathrm{Cd}$. Principal component analysis (PCA) showed that the sample distributions on PC1, accounting for $88.12 \%$ of total transcriptomic variance, were determined mainly by the rapeseed tissues, including the shoots or roots (Fig. 2D). In other words, the shoots and roots showed significantly distinct responses to high $\mathrm{Cd}$ and low $\mathrm{Cd}$. By contrast, the $\mathrm{PC} 2$ variance of 6.24\% was mainly attributed to varying Cd concentrations. The transcriptional response pattern under high 


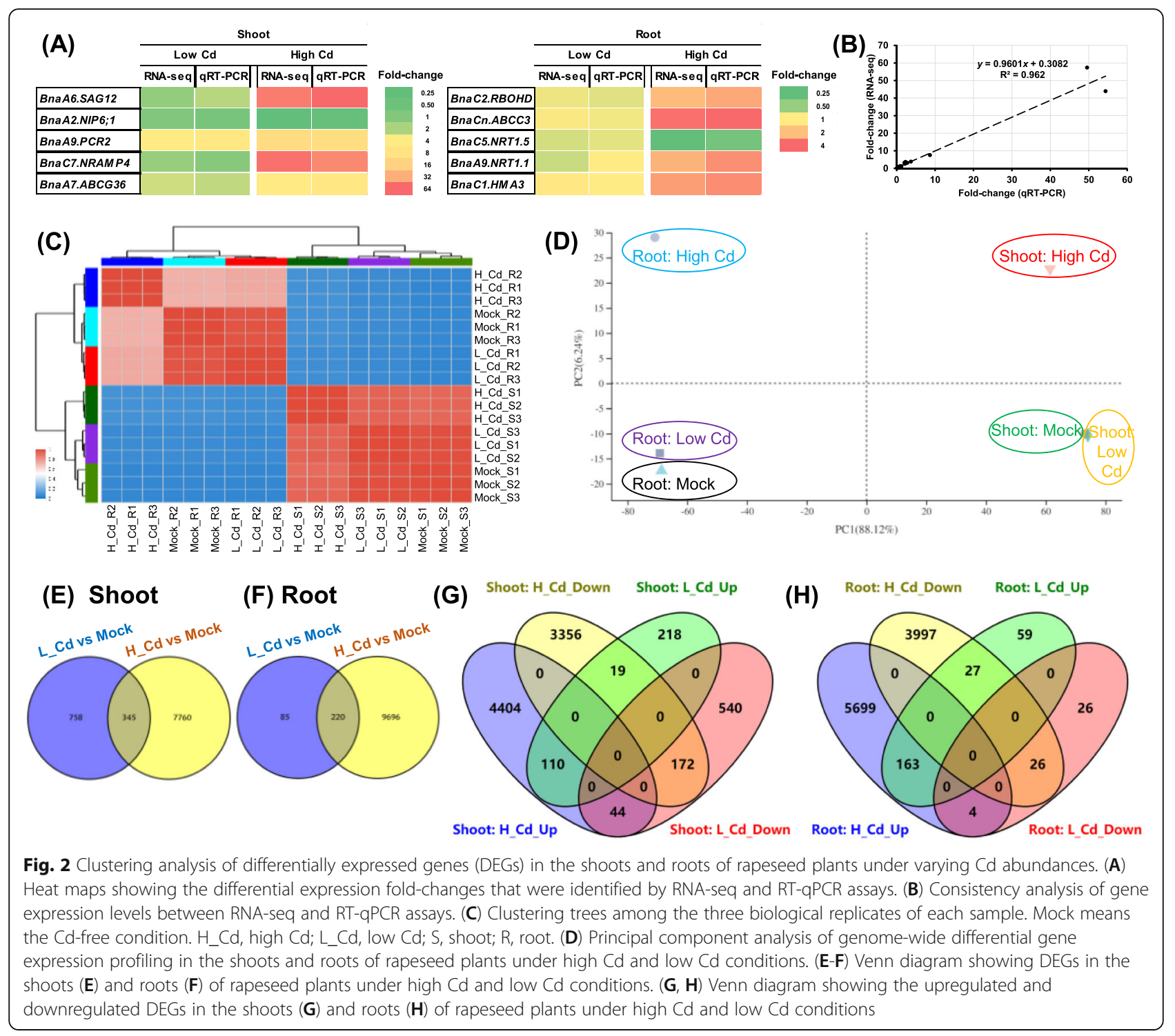

Cd condition was different from that under low $\mathrm{Cd}$, which was similar to the expression pattern under $\mathrm{Cd}$ free condition (Fig. 2D).

In the shoots, a total of 8105 and 1103 genes were identified to be differentially expressed under high $\mathrm{Cd}$ and low $\mathrm{Cd}$ conditions compared with the Cd-free (mock) condition, respectively (Fig. 2E). In the roots, a total of 9916 and 305 genes were identified to be differentially expressed under high $\mathrm{Cd}$ and low $\mathrm{Cd}$ conditions compared with the Cd-free (mock) condition, respectively (Fig. 2E). Further, we performed Venn diagram analysis to investigate the responsive patterns of these DEGs under different $\mathrm{Cd}$ concentrations. In general, the number of DEGs (471 genes) showing identical expression patterns was identified in both shoots (282 genes) and roots (189 genes) than those of the DEGs (94 genes) showing opposite expression patterns between high $\mathrm{Cd}$ and low Cd conditions (Fig. 2F, G).

The gene ontology (GO) enrichment analysis of functional significance allowed us to distinguish major biological functions of the DEGs under varying $\mathrm{Cd}$ abundances. In the shoots of rapeseed plants under low $\mathrm{Cd}$, we found that the highly enriched GO terms were mainly related to the biosynthesis of plant cell wall components, including lignin, hemicellulose, and xylan (Fig. 3A). However, in the shoots of rapeseed plants under high $\mathrm{Cd}$, the $\mathrm{GO}$ terms involving photosynthesis, nitrogen (including amine, urea, and ammonium) transport and response, and response to $\mathrm{Fe}^{2+}$ homeostasis were over-accumulated (Fig. 3B). Subsequently, we further investigated the differential GO categories in the roots between high $\mathrm{Cd}$ and low $\mathrm{Cd}$ conditions. In the 


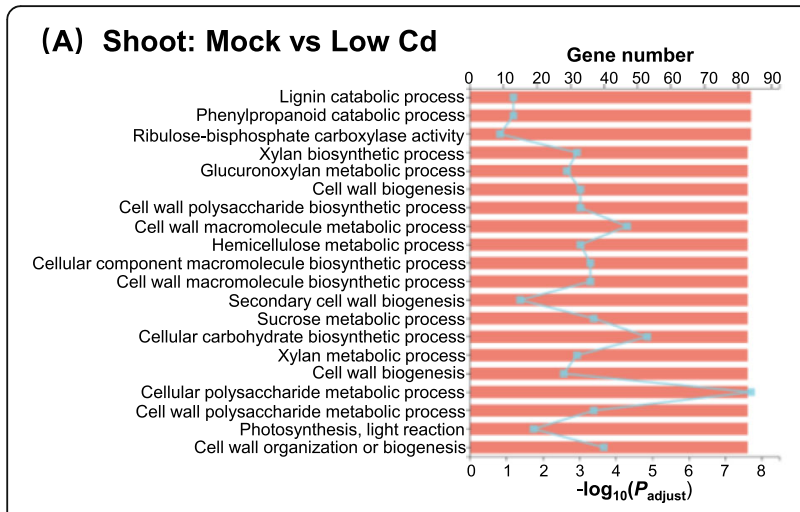

(C) Root: Mock vs Low Cd

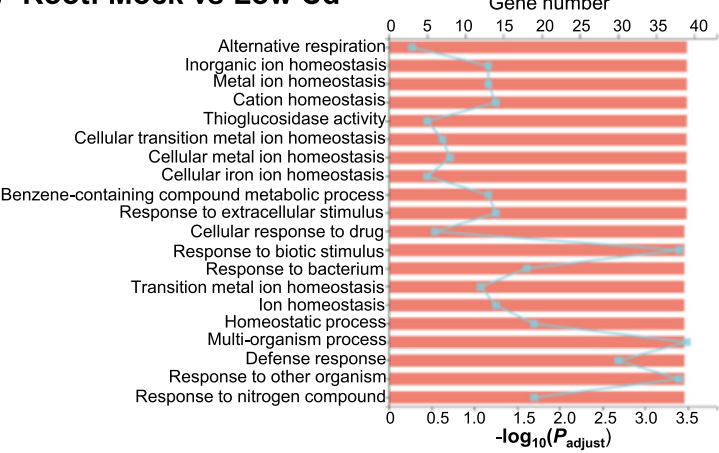

(B) Shoot: Mock vs High Cd Gene number

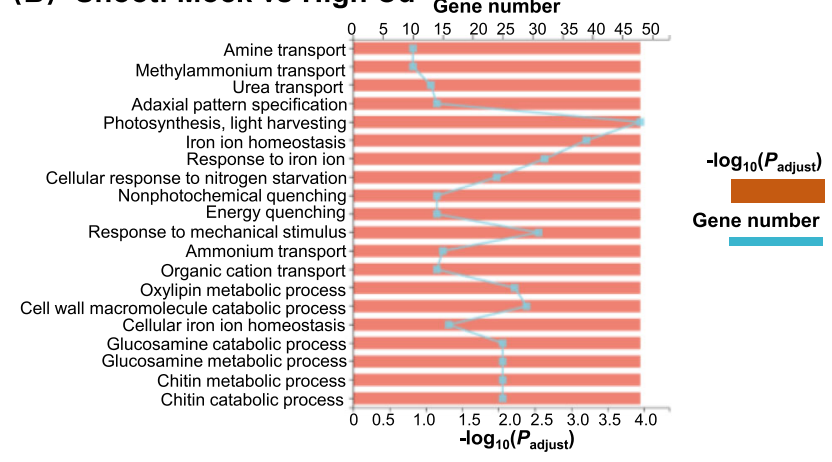

(D) Root: Mock vs High Cd

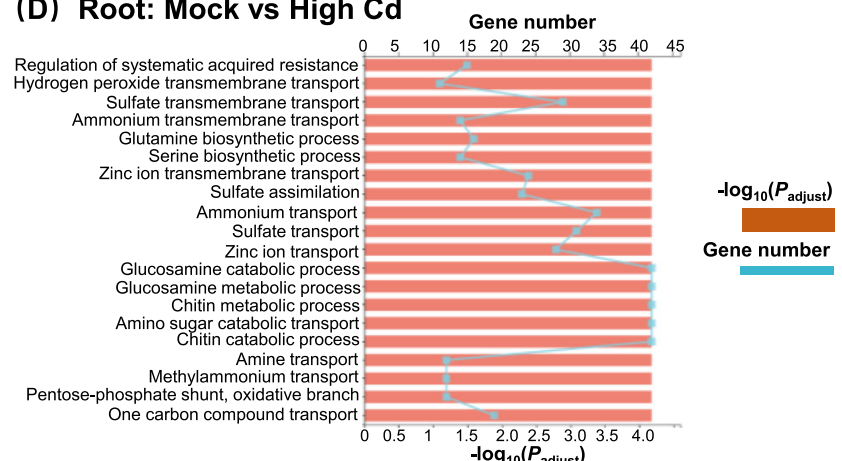

Fig. 3 Gene ontology (GO) enrichment analysis of the differentially expressed genes (DEGs) in rapeseed plants under varying $C d$ abundances. (AD) Highly accumulated GO terms in the shoots (A, B) and roots (C, D) of rapeseed plants under low $\mathrm{Cd}(\mathbf{A}, \mathbf{C})$ and high $\mathrm{Cd}(\mathbf{B}, \mathbf{D})$ conditions. Mock means the Cd-free condition

roots of rapeseed plants under low $\mathrm{Cd}$, three terms about cellular metal ion homeostasis, response to external stimulus, and defense response were highly accumulated (Fig. 3C). By contrast, the transport and metabolism of $\mathrm{Zn}^{2+}$, sulfate, and nitrogen (including ammonium and glutamate) were the most enriched GO groups in the roots of rapeseed plants under high $\mathrm{Cd}$ (Fig. 3D).

To identify the biological pathways that were active in B. napus during exposure to high $\mathrm{Cd}$ and low $\mathrm{Cd}$ conditions, we characterized the pathways in which the DEGs were involved in the KEGG database. Consistently, photosynthesis in the shoots and phenylpropanoid biosynthesis in the roots were the most active pathways under both high $\mathrm{Cd}$ and low $\mathrm{Cd}$ conditions (Fig. 4). Compared with the KEGG pathways identified under low $\mathrm{Cd}$, more pathways involving sulfur and nitrogen metabolism, phytohormone biosynthesis and signal transduction were characterized in both shoots and roots under high $\mathrm{Cd}$ condition (Fig. 4).

\section{Genome-wide identification and transcriptional} characterization of cd uptake transporters under high cd and low cd conditions

In the allotetraploid rapeseed genome $\left(A_{n} A_{n} C_{n} C_{n}\right)$, a total of $22 N R A M P$ transporter genes, including NRAM
$P 1$ to NRAMP6, were functionally annotated and identified in the transcriptome sequencing data. In this study, only eight members of the NRAMP families were identified to be differentially expressed under high $\mathrm{Cd}$ and low $\mathrm{Cd}$ (Fig. 5A). Among the NRAMP DEGs, it is noteworthy that both BnaC7.NRAMP4 (BnaC07g15960D) and BnaC8.NRAMP3 (BnaC08g34570D) were differentially responsive to high $\mathrm{Cd}$ and low $\mathrm{Cd}$ conditions. The expression of BnaC5.NRAMP6 (BnaC05g12190D) was repressed under both high $\mathrm{Cd}$ and low $\mathrm{Cd}$ conditions. In addition, the other NRAMP DEGs were upregulated in both shoots and roots under high $\mathrm{Cd}$. According to the gene co-expression network analysis result, BnaAn.NRAMP4 (BnaAnng14550D) was proposed to be the central NRAMP family member (Fig. $5 \mathrm{~B}$ ).

Among the genome-wide 27 YSLs that were identified in B. napus, BnaC7.YSL1 (BnaC07g38730D), the only one YSL homolog responsive to low $\mathrm{Cd}$, was upregulated in the shoots (Fig. 5C). Among the DEGs responsive to high Cd, four BnaYSL1s (BnaC1.YSL1/ BnaC01g15940D,BnaC3.YSL1/BnaC03g62050D,BnaA8.YSL1a/BnaA08g15130D, and BnaA8.YSL1b/ BnaA08g10710D) were downregulated only in the shoots, and other BnaYSL DEGs were induced by high $\mathrm{Cd}$ in both shoots and roots. The two homologs of YSL2s showed the highest expression abundances and 

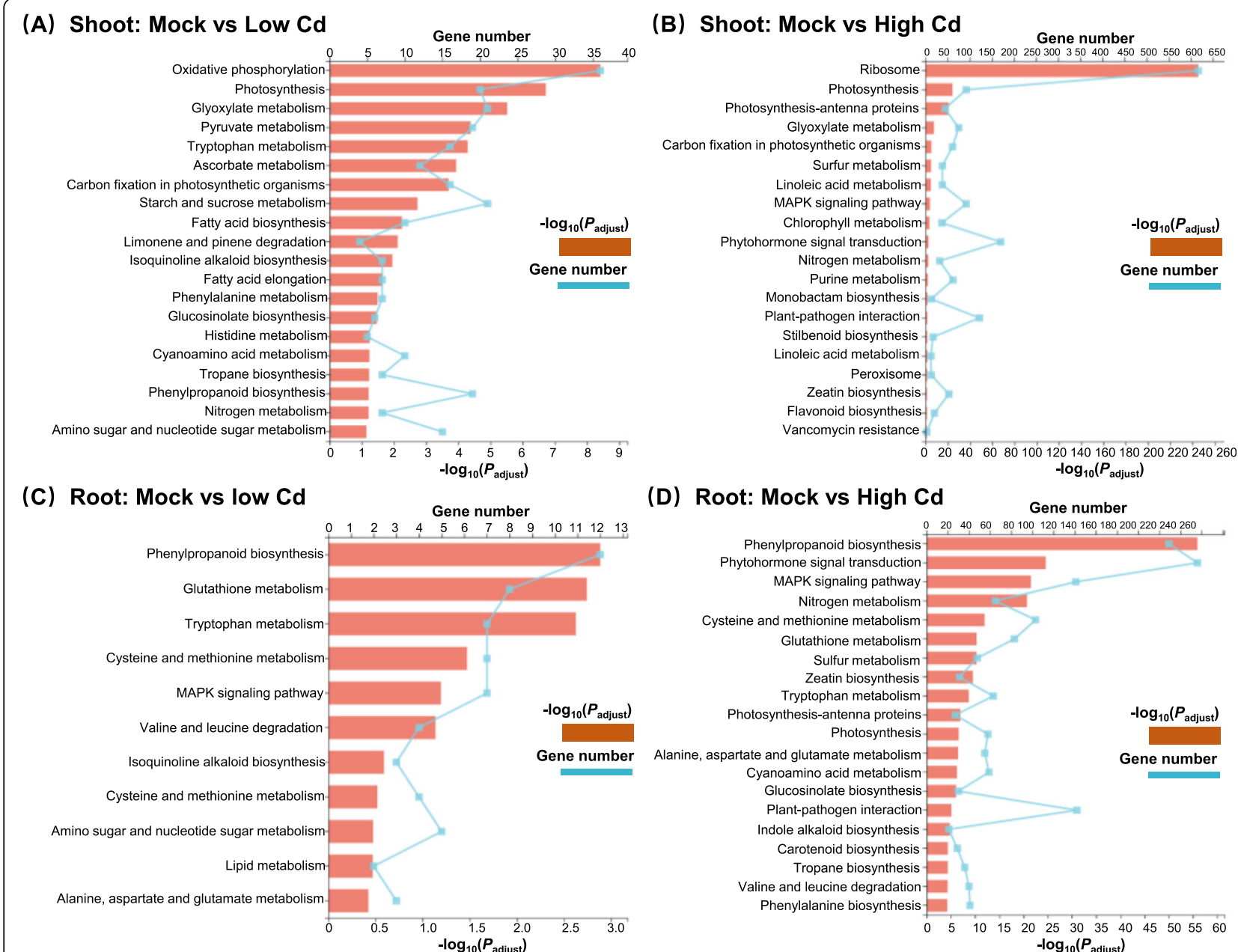

(D) Root: Mock vs High Cd

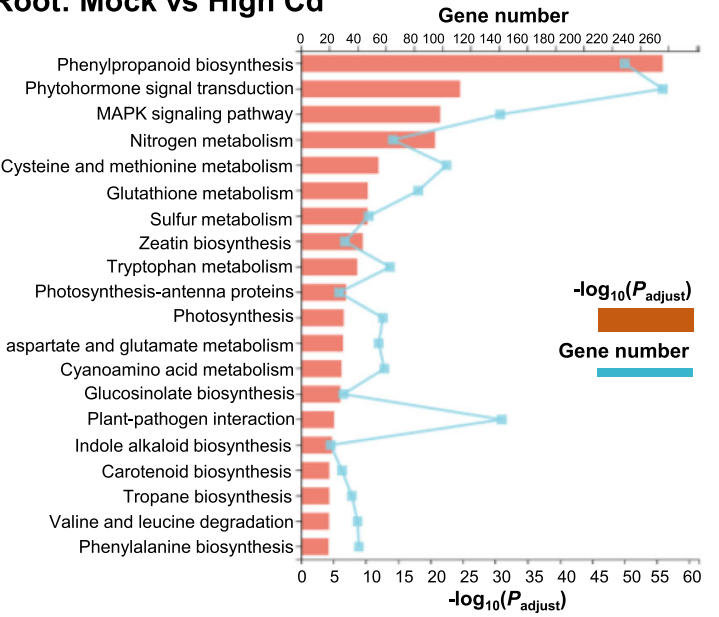

Fig. 4 KEGG pathway enrichment analysis of the differentially expressed genes (DEGs) in rapeseed plants under varying Cd abundances. (A-D) Highly accumulated KEGG pathways in the shoots $(\mathbf{A}, \mathbf{B})$ and roots $(\mathbf{C}, \mathbf{D})$ of rapeseed plants under low $\mathrm{Cd}(\mathbf{A}, \mathbf{C})$ and high $\mathrm{Cd}(\mathbf{B}, \mathbf{D})$ conditions. Mock means the Cd-free condition

largest fold-changes under high $\mathrm{Cd}$, especially in the roots. The gene co-expression network analysis showed that BnaCn.YSL2 (BnaCnng70180D) might be the core $Y S L$ family gene (Fig. 5D).

In this study, we identified a total of 14 IRT DEGs, which included 11 IRT1s, one IRT2, and two IRT3s, under high $\mathrm{Cd}$ and low $\mathrm{Cd}$ conditions (Fig. 6A). All the nine IRT DEGs that were identified under low $\mathrm{Cd}$ were upregulated, however, most of the 14 IRT DEGs that were identified under high $\mathrm{Cd}$ were downregulated, particularly in the roots (Fig. 4A). The gene co-expression network analysis showed that BnaA1.ITRT1c (BnaA01g35020D) might be the core IRT family gene (Fig. 6B).

In $B$. napus, we retrieved a total of 53 ZIP family genes. Based on the transcriptome sequencing data, we identified 20 BnaZIP DEGs, five members of which were only responsive to low $\mathrm{Cd}$. Among all the DEGs, a major proportion $(80 \%)$ was upregulated in the shoots or roots under high $\mathrm{Cd}$ except BnaC4.ZIP6 (BnaC04g14740D), BnaA5.ZIP6 (BnaA05g12290D),BnaA9.ZIP1O(BnaA09g25300D), and BnaCn.ZIP10 (BnaC04g14740D) that were repressed by high $\mathrm{Cd}$ only in the roots (Fig. 6C). Among the upregulated BnaZIP DEGs, BnaC5.ZIP1 (BnaC05g40440D) and BnaA9.ZIP10 (BnaA09g25300D) showed the highest expression abundances and largest fold-changes under high $\mathrm{Cd}$, and they were identified to be core members of BnaZIPs (Fig. 6D).

\section{Genome-wide identification and transcriptional characterization of vacuolar cd transporters under high cd and low cd conditions}

Among the genome-wide 32 HMAs in B. napus, a total of 17 HMA DEGs were identified. Among these DEGs, in general, the $H M A 2$ subfamily members showed much higher expression abundances than other subfamily members (Fig. 7A). Only four DEGs (BnaA7.HMA4/ BnaA07g36130D,BnaAn.HMA3/BnaAnng10870D, BnaCn.HMA3/BnaCnng78610D, and BnaA1.HMA6/ 

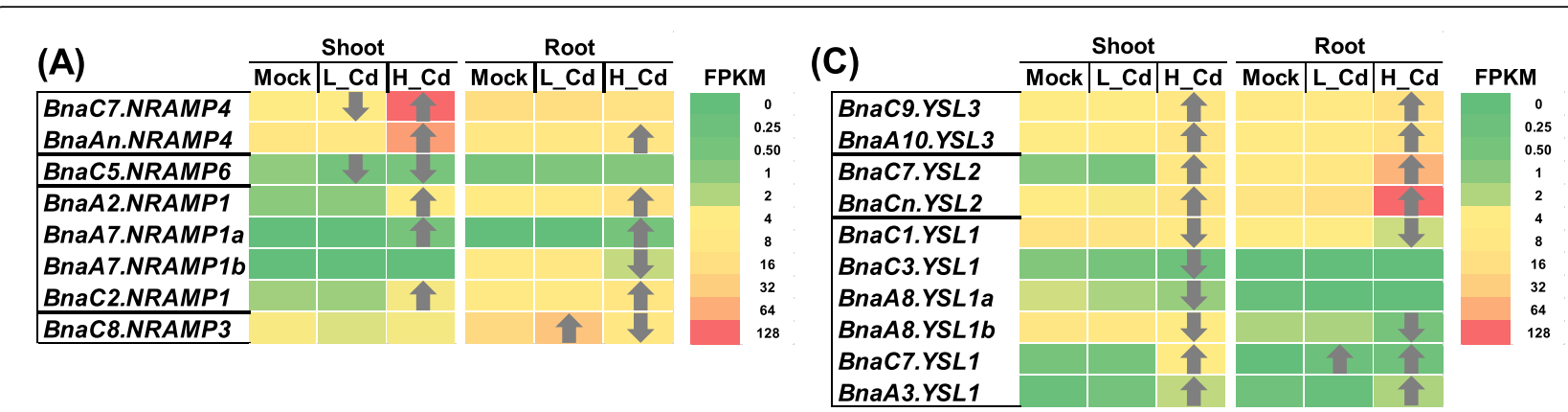

(B)

(D)

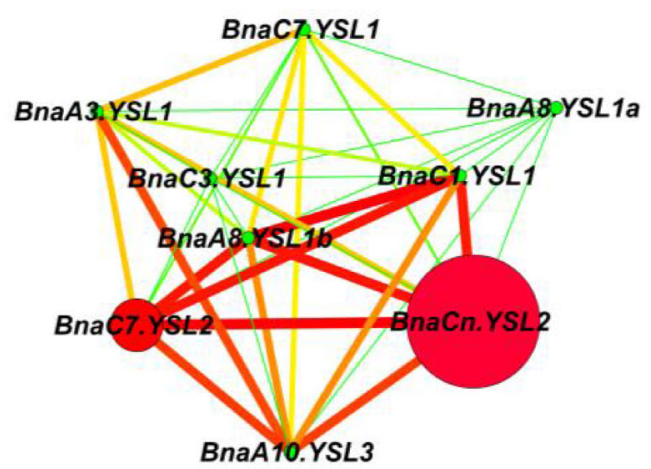

Fig. 5 Differential expression and co-expression network analysis of NRAMPS and YSLs under varying Cd abundances. (A-D) Differential expression

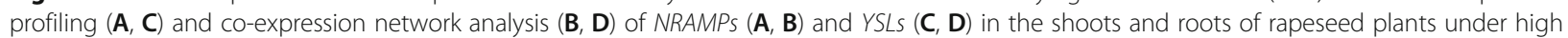
$\mathrm{Cd}$ and low $\mathrm{Cd}$ conditions. In the heat maps, the upward and downward arrows indicate the upregulation and downregulation of differentially expressed genes. In the gene co-expression networks, cycle nodes represent genes, and the size of the nodes represents the power of the interrelation among the nodes by degree value. Edges between two nodes represent interactions between genes. Mock means the Cd-free condition

BnaA01g03390D) were downregulated in the shoots or roots under high $\mathrm{Cd}$ or low $\mathrm{Cd}$, whereas the expression of other HMA DEGs was induced in both shoots and roots under high $\mathrm{Cd}$ (Fig. 7A). Gene co-expression network analysis showed that BnaA1.HMA2 (BnaA01g06430D) and BnaC7.HMA4 (BnaC07g02470D) might play a core role in $H M A$-mediated $\mathrm{Cd}$ transport (Fig. 7B).

In B. napus, a total of $314 \mathrm{ABC}$ transporter genes were identified, which included $47 A B C C$ members [31]. Among these ABCCs, there were two and 17 DEGs identified under low $\mathrm{Cd}$ and high $\mathrm{Cd}$ conditions, respectively (Fig. 7C). In general, the ABCC3 DEGs showed higher expression levels than other members. Under low Cd, two DEGs, BnaC1.ABCC7 (BnaC01g37990D) and BnaC1.ABCC3 (BnaC01g37970D), were upregulated only in the shoots, whereas they showed no significant changes under high $\mathrm{Cd}$. Under high $\mathrm{Cd}$, all the 17 DEGs were upregulated, whereas they were not differentially expressed under low $\mathrm{Cd}$. Through gene co-expression network analysis, BnaC3.ABCC3b (BnaC03g73620D) was identified to be the core $A B C C$-mediated gene regulating vacuolar $\mathrm{Cd}$ sequestration (Fig. 7D). Further, we investigated the differential expression of $A B C G$ s under high $\mathrm{Cd}$ and low $\mathrm{Cd}$ conditions. The result showed that all the 41 DEGs that were identified were only responsive to high Cd (Fig. 7E). Among the $A B C G$ DEGs, the $A B C G 35$ and $A B C G 36$ subgroups showed the highest expression levels. A larger proportion of the DEGs were upregulated in both shoots (57\%) and roots (72\%) under high $\mathrm{Cd}$. Through gene co-expression network analysis, BnaCn.ABCG36 (BnaCnng64010D) and BnaC5.ABCG35 (BnaC05g11500D) were identified to be the core $A B C C$ mediated genes regulating $\mathrm{Cd}$ efflux in the shoots and roots, respectively (Fig. 7F).

According to the rapeseed genome information, we retrieved a total of $17 C A X$ family genes. All the genomewide differentially expressed BnaCAXs were identified under high $\mathrm{Cd}$, whereas low $\mathrm{Cd}$ did not cause the differential expression of BnaCAXs (Fig. 7G). In general, the CAX1 subgroup members had much higher expression abundances than other subgroup. In the shoots, all the three identified CAX DEGs, including BnaC4.CAX1 (BnaC04g45720D), BnaA1.CAX2 (BnaA01g29870D), and BnaA1.CAX2 (BnaC01g37750D), were upregulated. In the roots, all the four identified $C A X$ DEGs, including BnaA4.CAX1 (BnaA04g21850D), BnaC4.CAX1 (BnaC04g45720D), BnaC3.CAX5 (BnaC03g70750D), and BnaA8.CAX5 (BnaA08g00350D), were downregulated. Among the six CAX DEGs, only BnaC4.CAX1 was 


\begin{tabular}{|c|c|c|c|c|c|c|c|}
\hline \multirow{2}{*}{$\begin{array}{c}\text { (A) } \\
\text { BnaC7.IRT2 }\end{array}$} & \multicolumn{3}{|c|}{ Shoot } & & \multicolumn{2}{|l|}{ Root } & \multirow{2}{*}{ FPKM } \\
\hline & & & & & - & & \\
\hline BnaCn.IRT1a & & & & & & & $\begin{array}{l}0.25 \\
0.50\end{array}$ \\
\hline BnaCn.IRT1b & & & & & & $\pi$ & \\
\hline BnaA1.IRT1a & & & & & 수 & 1 & \\
\hline BnaA1.IRT1b & & & & & 숫 & 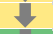 & \\
\hline BnaA3.IRT1 & & & & & 수 & & \\
\hline BnaCn.IRT1c & & & & & & 7 & \\
\hline Bnac1.IRT1 & & & & & 1 & 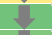 & \\
\hline Bnac7.IRT1a & & & 수 & & & $y$ & \\
\hline BnaCn.IRT1d & & & 술 & & & $v$ & \\
\hline BnaC7.IRT1b & & & $\boldsymbol{1}$ & & 1 & 1 & \\
\hline BnaA1.IRT1c & & & & & & $\nabla$ & \\
\hline BnaA9.IRT3 & & & 1 & & & & \\
\hline BnaA1.IRT3 & & 1 & 1 & & & 1 & \\
\hline
\end{tabular}

(B)

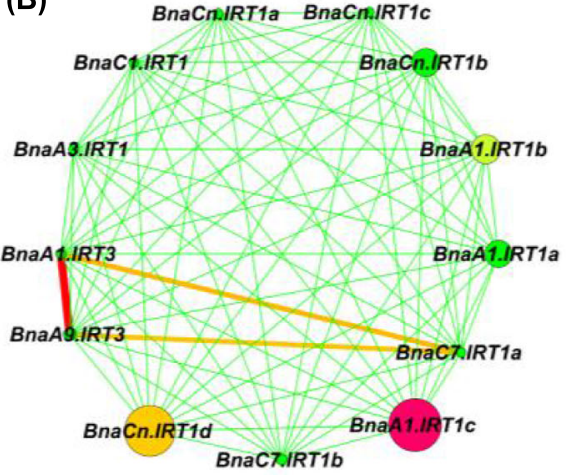

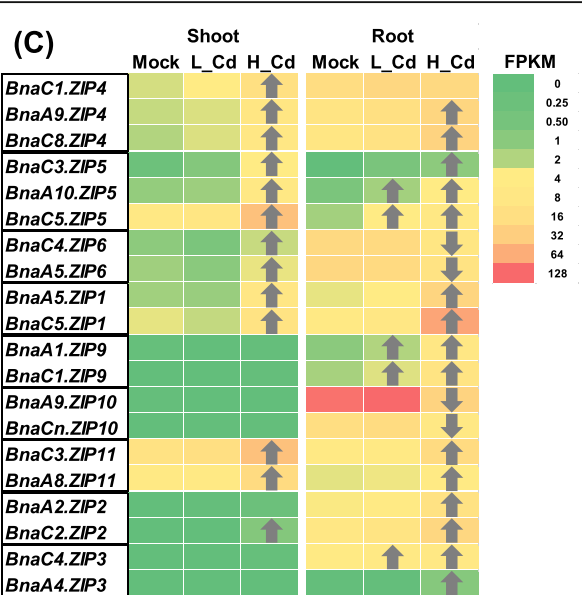

(D)

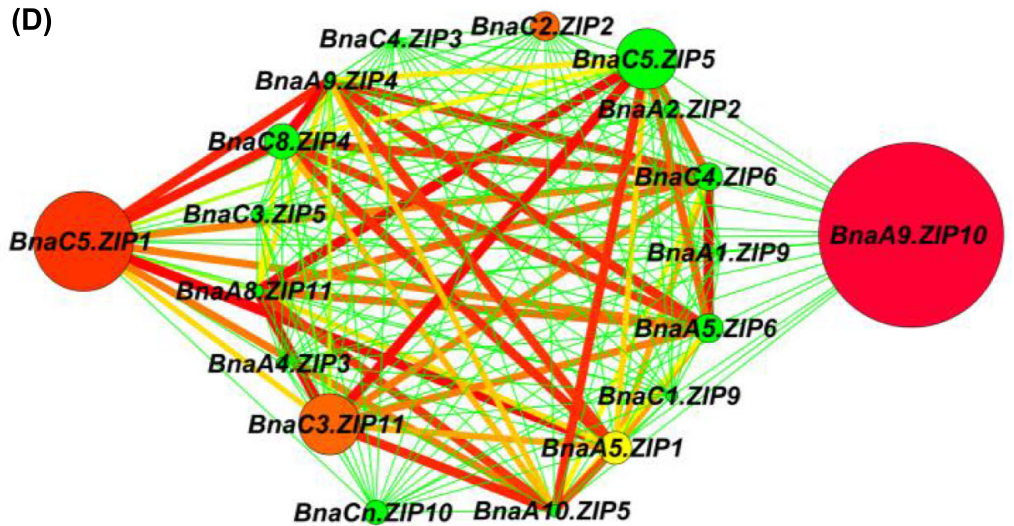

Fig. 6 Differential expression and co-expression network analysis of IRTs and ZIPs under varying Cd abundances. (A-D) Differential expression profiling $(\mathbf{A}, \mathbf{C})$ and co-expression network analysis (B, D) of IRTS $(\mathbf{A}, \mathbf{B})$ and ZIPS $(\mathbf{C}, \mathbf{D})$ in the shoots and roots of rapeseed plants under high Cd and low $\mathrm{Cd}$ conditions. In the heat maps, the upward and downward arrows indicate the upregulation and downregulation of differentially expressed genes. In the gene co-expression networks, cycle nodes represent genes, and the size of the nodes represents the power of the interrelation among the nodes by degree value. Edges between two nodes represent interactions between genes. Mock means the Cd-free condition

differentially expressed in both shoots and roots, whereas it showed opposite expression patterns between shoots (upregulated) and roots (downregulated) (Fig. $7 \mathrm{H})$.

\section{Genome-wide identification and transcriptional characterization of other cd transporters under high cd and low cd conditions}

In allotetraploid B. napus, a total of 33 MTPs were annotated [32], and there were three and nine members differentially expressed under low $\mathrm{Cd}$ and high $\mathrm{Cd}$ conditions, respectively. Under low Cd, three MTP DEGs (BnaC4.MTPB/BnaC04g40510D,

BnaA4.MTPB/ BnaA04g28640D, and BnaC2.MTPA2/BnaC02g06740D) were identified, and all of them were downregulated. Under high Cd, a total of MTP DEGs were characterized, four and five of which were upregulated and downregulated, respectively (Fig. 8A). It was noteworthy that two BnaMTPB DEGs showed significantly differential responsive patterns under high $\mathrm{Cd}$ and low $\mathrm{Cd}$ conditions: both of them were downregulated under low $\mathrm{Cd}$ whereas they were upregulated under high Cd (Fig. 8A). Gene co-expression network analysis showed that BnaA5.MTP11 was the core family gene (Fig. 8B), which presented the highest expression level and largest foldchange (Fig. 8A).

In Arabidopsis, the $P C R$ family contained 12 subgroups, namely PCR1-PCR12 (https://www.arabidopsis. org/index.jsp). In this study, three PCR DEGs were identified under low $\mathrm{Cd}$, and all of them were upregulated. By contrast, a total of 14 PCR DEGs were characterized under high $\mathrm{Cd}$, and 10 (71.42\%) of them were upregulated except the downregulated BnaPCR6 homologs and BnaA4.PCR10 (BnaA04g23620D) (Fig. 8C). Based on the 


\section{(A)}

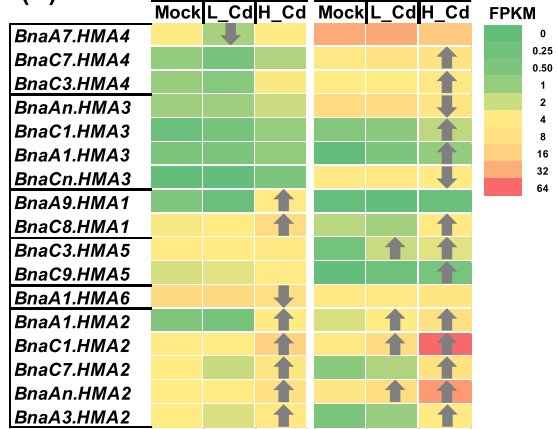

(B)
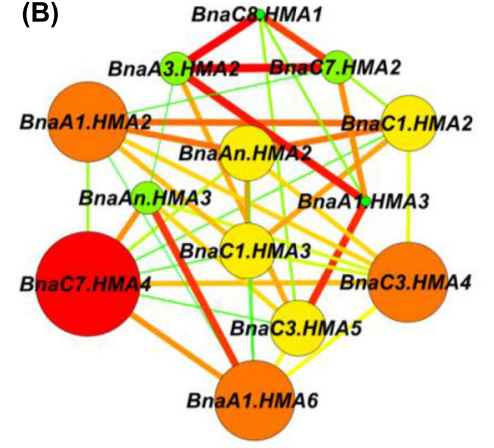

(C) $\frac{\text { Shoot }}{\text { Mock }\left|L_{-} C d\right| H_{-} \text {Cd }} \frac{\text { Root }}{\text { Mock }\left|L_{-} C d\right| H_{-} \text {Cd }}$ FPKM

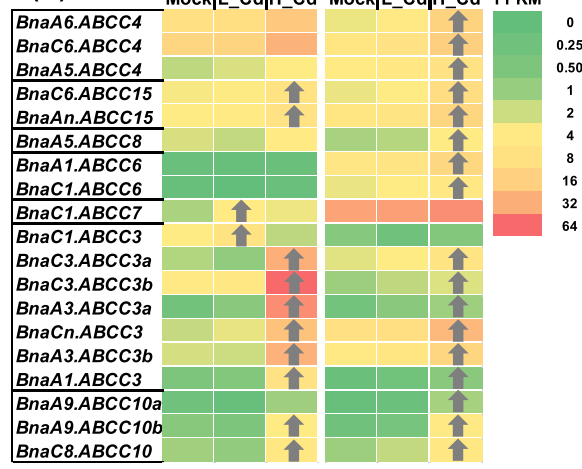
(D)

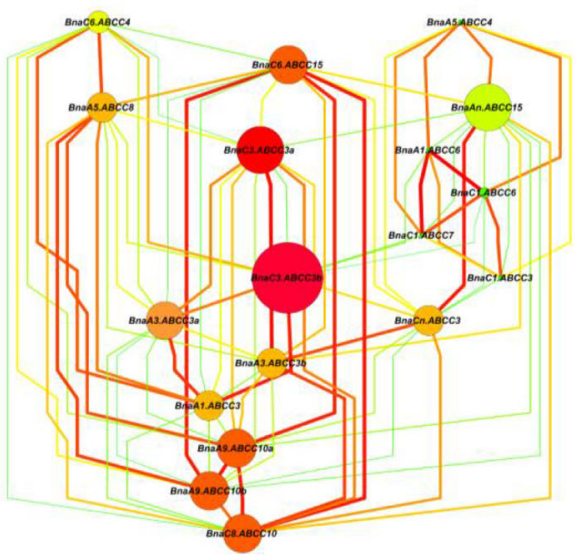

(E)

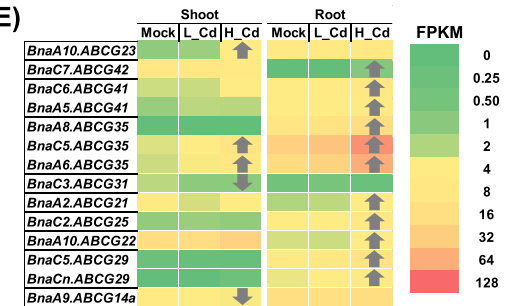
$\frac{1}{B \text { naAG9.ABCG14a }}$

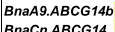

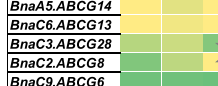
BnaA10.ABCG6 $\frac{B n a A 4 . A B C G 27}{B \text { BnaAGABCCG18 }}$ BnaC4.ABCG18 BnaA4.ABCG18 BnaA4.ABCG16

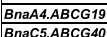
BnaC5.ABCG40
BnaA6.ABCG40 \begin{tabular}{l} 
BnaAG.ABCG 40 \\
BnaAS.ABCG40 \\
\hline
\end{tabular} BnaASn.ABCG 24 BnaA8.ABCG 24 BnaA7.ABCG 36 BnaA4.ABCG2 BnaC4.ABCG2 BnaC4.ABCG33 BnaA5.ABCG33

(F)

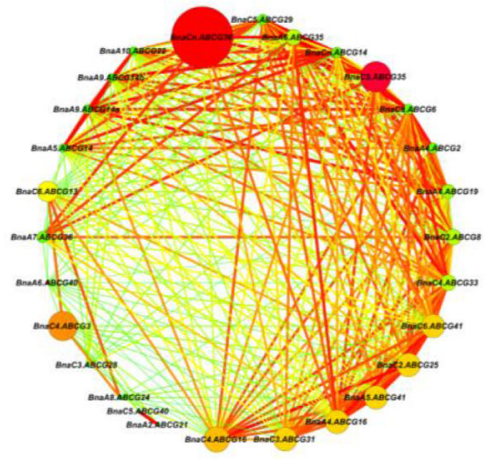

(G) Shoot Root

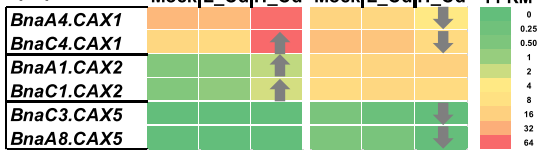

(H)

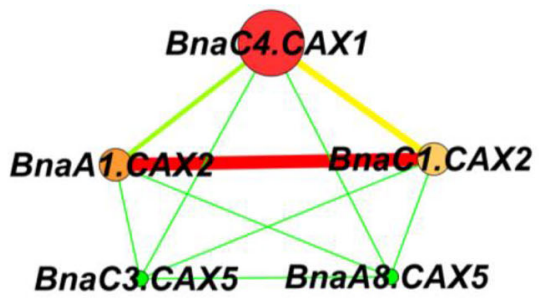

Fig. 7 (See legend on next page.) 
(See figure on previous page.)

Fig. 7 Differential expression and co-expression network analysis of HMAs, ABCCS, and CAXs under varying Cd abundances. (A-H) Differential expression profiling $(\mathbf{A}, \mathbf{C}, \mathbf{E}, \mathbf{G})$ and co-expression network analysis $(\mathbf{B}, \mathbf{D}, \mathbf{F}, \mathbf{H})$ of $\operatorname{HMAs}(\mathbf{A}, \mathbf{B}), \operatorname{ABCCS}(\mathbf{C}, \mathbf{D}), A B C G s(\mathbf{E}, \mathbf{F})$ and $C A X s(\mathbf{G}, \mathbf{H})$ in the shoots and roots of rapeseed plants under high $\mathrm{Cd}$ and low $\mathrm{Cd}$ conditions. In the heat maps, the upward and downward arrows indicate the upregulation and downregulation of differentially expressed genes. In the gene co-expression networks, cycle nodes represent genes, and the size of the nodes represents the power of the interrelation among the nodes by degree value. Edges between two nodes represent interactions between genes. Mock means the Cd-free condition

gene co-expression network analysis, BnaA9.PCR2a (BnaA09g45360D) was proposed to be the central PCR member (Fig. 8D).

\section{Genome-wide identification and transcriptional} characterization of cd chelators under high cd and low cd conditions

Plant MTs are classified into four types according to the arrangement of their cystein residues [33], including the MT1, MT2, MT3, and MT4 subfamilies [34]. However, we identified the differential expression of MTs only under high Cd (Fig. 9A). Among the six BnaMT2 DEGs, three BnaMT2s were downregulated and four BnaMT2s were upregulated in the shoots or roots. Gene coexpression network analysis revealed that BnaA3.MT2, showing the highest expression level and largest foldchange, was identified to be the core member of MTs (Fig. 9B).

In the genome-wide BnaPCS family genes, we only identified four DEGs, all of which were responsive to high Cd (Fig. 9C). However, three of them, including BnaA9.PCS1, BnaC9.PCS1a, and BnaC9.PCS1b, were

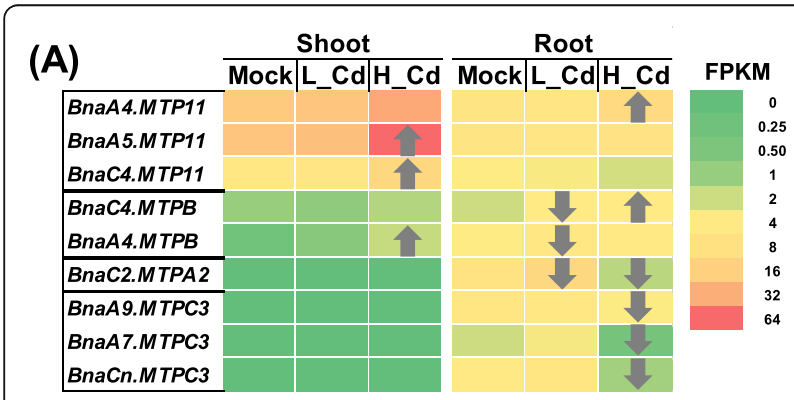

(B)

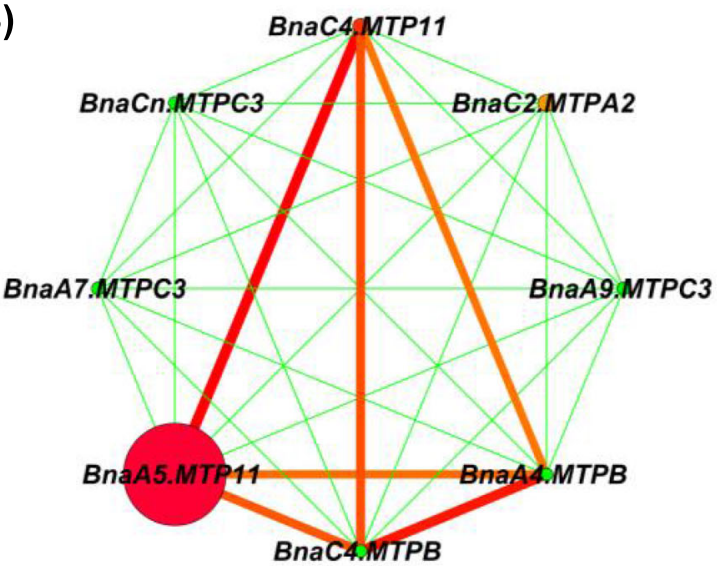

(C)

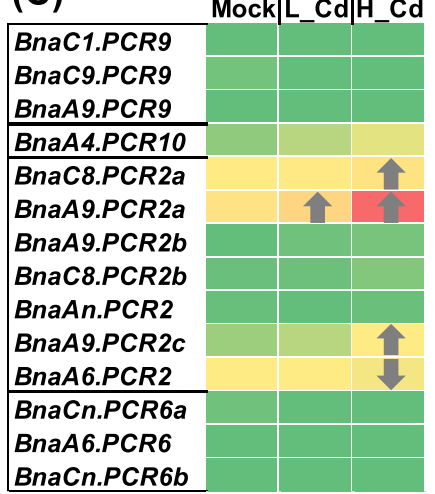

Root

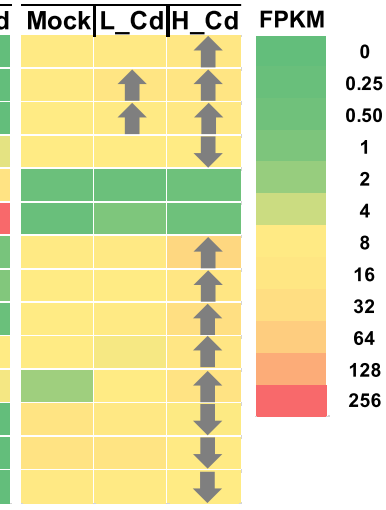

(D)

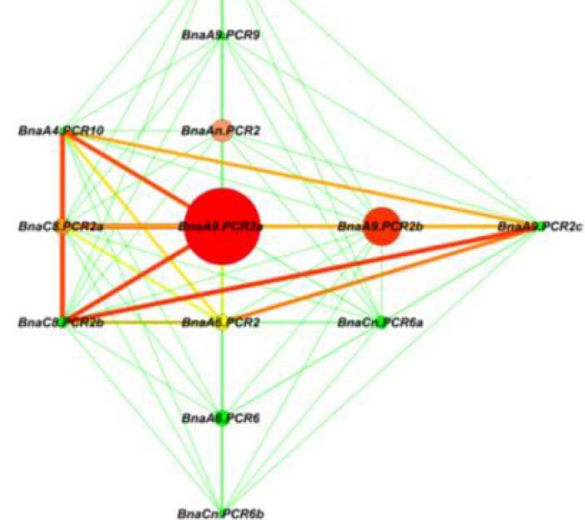

Fig. 8 Differential expression and co-expression network analysis of MTPs and PCRs under varying Cd abundances. (A-D) Differential expression profiling $(\mathbf{A}, \mathbf{C})$ and co-expression network analysis $(\mathbf{B}, \mathbf{D})$ of MTPs $(\mathbf{A}, \mathbf{B})$ and PCRs $(\mathbf{C}, \mathbf{D})$ in the shoots and roots of rapeseed plants under high Cd and low $\mathrm{Cd}$ conditions. In the heat maps, the upward and downward arrows indicate the upregulation and downregulation of differentially expressed genes. In the gene co-expression networks, cycle nodes represent genes, and the size of the nodes represents the power of the interrelation among the nodes by degree value. Edges between two nodes represent interactions between genes. Mock means the Cd-free condition 

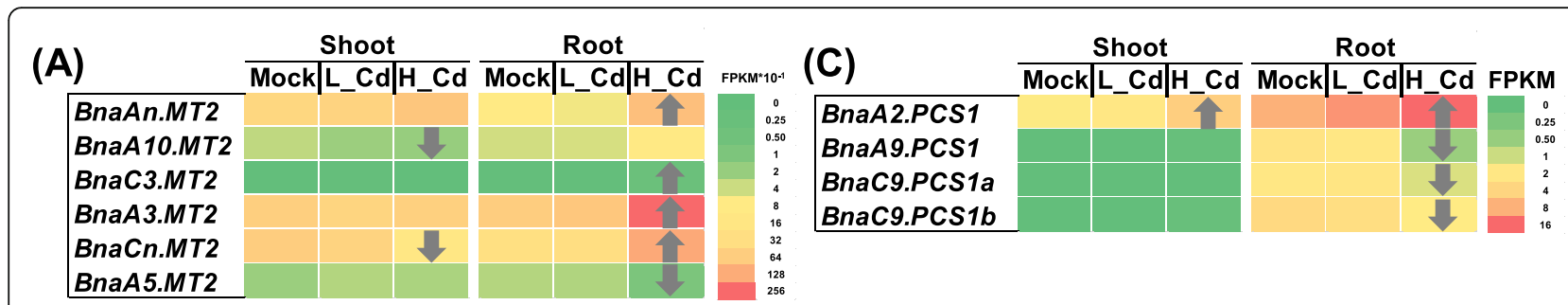

(B)

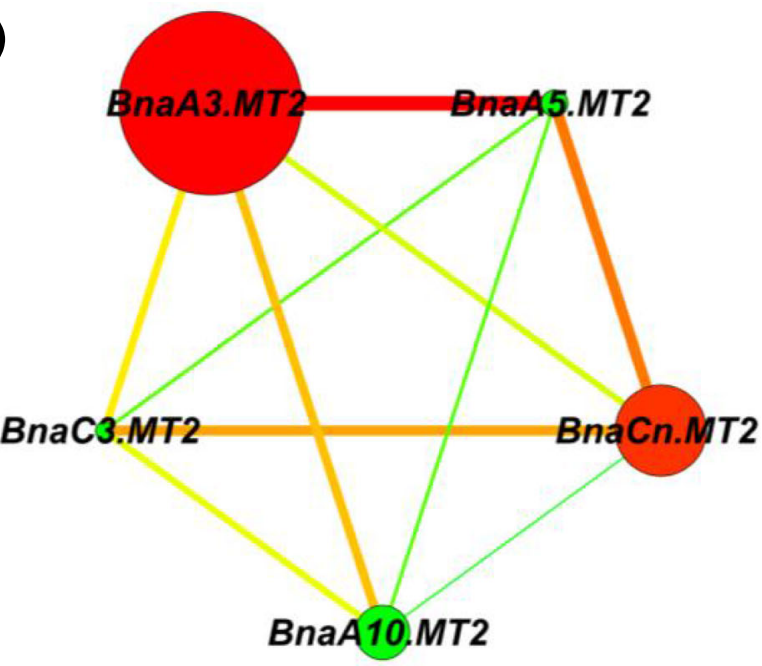

(D)

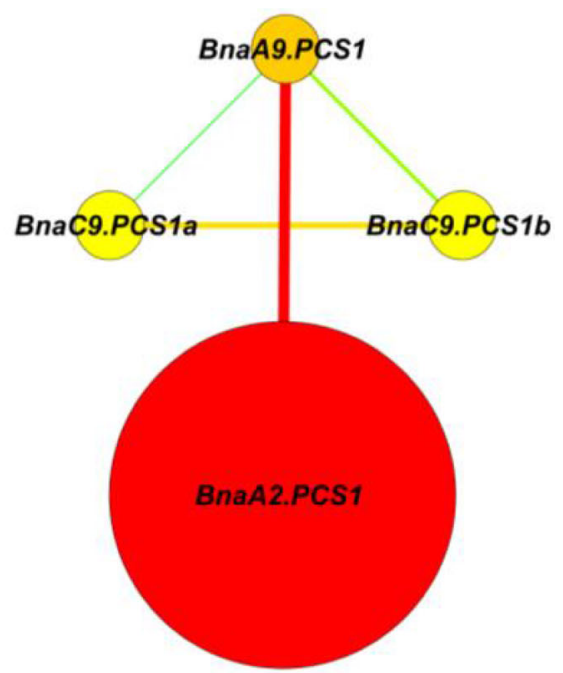

Fig. 9 Differential expression and co-expression network analysis of MTs and PCSs under varying Cd abundances. (A-D) Differential expression profiling $(\mathbf{A}, \mathbf{C})$ and co-expression network analysis (B, D) of MTs $(\mathbf{A}, \mathbf{B})$ and PCSs $(\mathbf{C}, \mathbf{D})$ in the shoots and roots of rapeseed plants under high Cd and low $\mathrm{Cd}$ conditions. In the heat maps, the upward and downward arrows indicate the upregulation and downregulation of differentially expressed genes. In the gene co-expression networks, cycle nodes represent genes, and the size of the nodes represents the power of the interrelation among the nodes by degree value. Edges between two nodes represent interactions between genes. Mock means the Cd-free condition

downregulated, and only BnaA2.PCS1 was upregulated in both shoots and roots under high $\mathrm{Cd}$. Both gene expression pattern and co-expression network analysis revealed that BnaA2.PCS1 was the core gene that potentially functioned in the $\mathrm{Cd}$ detoxification process (Fig. 9D).

\section{Genome-wide transcriptional characterization of other element transporters under high cd and low cd conditions}

In order to identify the effect of exogenous vary $\mathrm{Cd}$ abundances on other essential element metabolism, genome-wide transcriptional profiling of the transporter genes of nitrate, phosphate, potassium, sodium, magnesium, copper, and boron nutrients (Fig. 10). In general, the expression of these above-mentioned transporter genes was not significantly changed under low $\mathrm{Cd}$, whereas high $\mathrm{Cd}$ induced extensive alteration of their transcriptional levels (Fig. 10). Under both high $\mathrm{Cd}$ and low Cd conditions, the DEGs of dual-affinity nitrate transporter genes (BnaNRT1.1 s/BnaNPF6.3s) and twocomponent high-affinity nitrate transporter genes $(B n a N R T 2.1 \mathrm{~s}$ and BnaNAR2.1s/BnaNRT3.1s) were downregulated (Fig. 10A). Meanwhile, high Cd repressed the expression of xylem-loading nitrate transporter genes (BnaNRT1.5 s/BnaNPF7.3s) whereas induced the expression of xylem-unloading nitrate transporter genes (BnaNRT1.8 s/BnaNPF7.2s) (Fig. 10A). The expression of NRT1.7/NPF2.13 responsible for source-to sink remobilization of nitrate was increased in the shoots under high Cd (Fig. 10A). Under high Cd, the expression of phosphate transporter genes, including BnaPHT1;1s, BnaPHT1;3s, BnaPHT1;8s, and BnaPHT1;9s, was downregulated in the roots. However, the expression levels of BnaPHT1;4s were significantly increased in both shoots and roots (Fig. 10B). The differential expression of some potassium transporter genes, including the chloroplast-localized $\mathrm{K}^{+}$efflux transporter gene KEA $\left(K^{+}\right.$ efflux antiporter), the vacuolar $\mathrm{K}^{+}$influx transporter gene KCO (two-pore $K^{+}$channel), the plasma membrane-localized $\mathrm{K}^{+}$influx transporter genes $A K T$ (Arabidopsis $\mathrm{K}^{+}$transporter) and, and the $\mathrm{K}^{+}$efflux gene SKOR (stelar $K^{+}$outward rectifier), was also observed only under high $\mathrm{Cd}$, and most of the DEGs were downregulated particularly in the roots (Fig. 10C). HKT1 (high-affinity $\mathrm{K}^{+}$transporter 1 ) is reported to be involved 


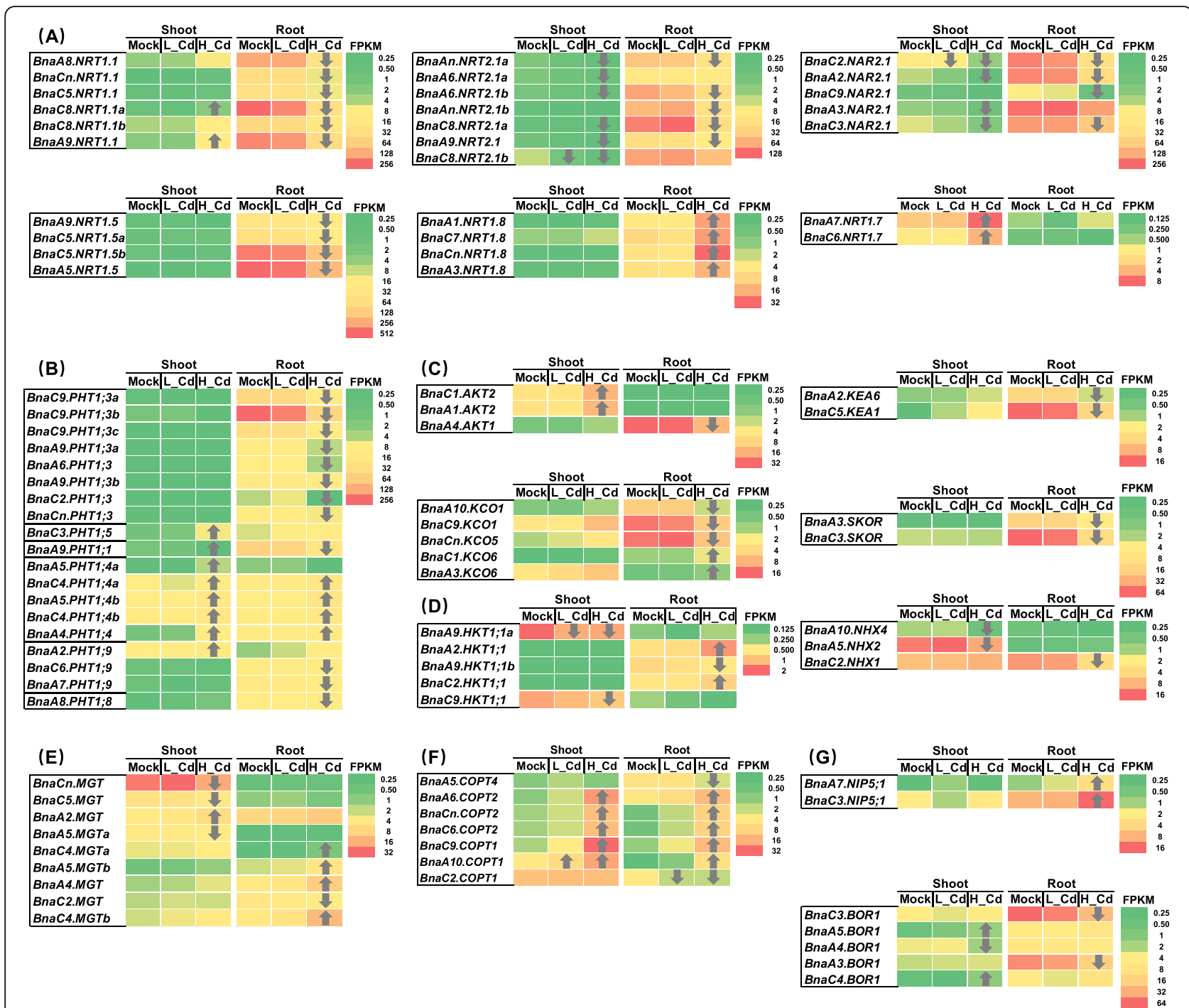

Fig. 10 Differential expression of some essential element transporter genes under varying Cd abundances. (A-F) Differential expression profiling of transporter genes of nitrate $(\mathbf{A})$, phosphate $(\mathbf{B})$, potassium $(\mathbf{C})$, sodium $(\mathbf{D})$, magnesium $(\mathbf{E})$, copper $(\mathbf{F})$, and boron $(\mathbf{G})$ nutrients in the shoots and roots of rapeseed plants under high $\mathrm{Cd}$ and low $\mathrm{Cd}$ conditions. In the heat maps, the upward and downward arrows indicate the upregulation and downregulation of differentially expressed genes. Mock means the Cd-free condition

in the root xylem $\mathrm{Na}^{+}$unloading in dicots, and the expression of BnaHKT1s was increased mainly in the roots, and the vacuolar $\mathrm{Na}^{+}$influx transporter genes, including BnaC2.NHX1, BnaA5.NHX2, and BnaA10.NHX4, were downregulated (Fig. 10D). In terms of the magnesium transporter (MGT) genes, the MGT DEGs were upregulated mainly in the roots and were downregulated mainly in the shoots (Fig. 10E). The general expression of copper transporter (COPT) genes was increased in both shoots and roots under high $\mathrm{Cd}$ (Fig. 10F). Eventually, we investigated the differential expression of a root boron influx channel gene NIP5;1 and a root xylem boron loading transporter gene BOR1, and the RNA-seq result showed that BnaNIP5;1 $s$ and
BnaBOR1s were upregulated and downregulated in the roots, respectively (Fig. 10G).

\section{Discussion}

Contaminated soils in the environment usually have a heterogeneous distribution of heavy metals [35], which leads to high and low metal abundances at different soil sites. Previous studies, mainly focusing on the responses of plants to high $\mathrm{Cd}$, lack systematic dissection into the differential responses of plants to high $\mathrm{Cd}$ and low $\mathrm{Cd}$ abundances. In the study, B. napus, a promising metalhyperaccumulating crop species, was hydroponically grown under high $\mathrm{Cd}$ and low $\mathrm{Cd}$ conditions. Subsequently, the ionomic homeostasis and transcriptomic 
profiling were investigated to achieve an understanding of differential physiological and molecular responses to varying $\mathrm{Cd}$ abundances and identify the core $\mathrm{Cd}$ transporter genes among multi-copy gene families in allotetraploid rapeseed. The findings obtained in this study can be used as a guidance for the genetic improvement of plant $\mathrm{Cd}$ resistance and accumulation under high $\mathrm{Cd}$ and low $\mathrm{Cd}$ conditions.

\section{Differential ionomic responses of $B$. napus to high cd and low cd imply complex interaction between nutrient elements and $\mathrm{cd}$}

Under both low $\mathrm{Cd}$ and high $\mathrm{Cd}$ conditions, much higher $\mathrm{Cd}$ concentrations were observed in the roots than in the shoots (Fig. 1G), and it might be a smart defensive reaction against $\mathrm{Cd}$ : plants maintain shoot growth and photosynthesis through root $\mathrm{Cd}$ retention. The differences in the $\mathrm{Cd}$ concentrations within rapeseed plants were much smaller than those in the hydroponic solution between high $\mathrm{Cd}$ and low $\mathrm{Cd}$ conditions (Fig. 1G). In this study, the $\mathrm{Cd}^{2+}$ concentration of $0.50 \mu \mathrm{M}$ did not cause severe phytotoxicity, which might not restrain the $\mathrm{Cd}$ accumulation in rapeseed plants. Therefore, the smaller differences in the tissue Cd concentrations might be attributed to low $\mathrm{Cd}$ accumulation of rapeseed plants under high $\mathrm{Cd}$, which could be thought of to be a smart defensive reaction of rapeseed plants against $\mathrm{Cd}$ toxicity.

According to the ion-responsive patterns under high $\mathrm{Cd}$ and low $\mathrm{Cd}$, the other eight cations were categorized into five groups: (i) $\mathrm{K}^{+}$, (ii) $\mathrm{Ca}^{2+}$ and $\mathrm{Mg}^{2+}$, (iii) $\mathrm{Fe}^{2+}$, $\mathrm{Zn}^{2+}$, and $\mathrm{Cu}^{2+}$, (iv) $\mathrm{Mn}^{2+}$, and (v) $\mathrm{Na}^{+}$(Fig. $1 \mathrm{H}-\mathrm{O}$ ). The $\mathrm{K}^{+}$concentrations, hardly affected by low $\mathrm{Cd}$, were significantly decreased in both shoots and roots under high $\mathrm{Cd}$ (Fig. $1 \mathrm{H}$ ), and it indicated that high $\mathrm{Cd}$ severely inhibited total $\mathrm{K}^{+}$uptake, which was confirmed by the decreased expression of BnaAKTs in the roots (Fig. 10C). Therefore, increasing $\mathrm{K}^{+}$supply is a strategy to improve the tolerance of plants exposed to high Cd toxicity [36], and $\mathrm{K}^{+}$-mitigated high $\mathrm{Cd}$ toxicity is related to the enhancement of $\mathrm{Cd}$ fixation in the root cell wall [37]. In terms of both $\mathrm{Ca}^{2+}$ and $\mathrm{Mg}^{2+}$ in the shoots, their concentrations were significantly decreased under low $\mathrm{Cd}$ whereas were significantly increased under high $\mathrm{Cd}$ (Fig. 1I, J). However, the concentrations of root $\mathrm{Ca}^{2+}$ and $\mathrm{Mg}^{2+}$ showed no significant changes under both high $\mathrm{Cd}$ and low $\mathrm{Cd}$ (Fig. 1I, J), which indicated that high $\mathrm{Cd}$ contributed to the translocation of $\mathrm{Ca}^{2+}$ and $\mathrm{Mg}^{2+}$ from roots to shoots, whereas this process was repressed by low $\mathrm{Cd}$. $\mathrm{CaCl}_{2}$ induces reduction of $\mathrm{Cd}$ accumulation, improves cell membrane stability, and increases the antioxidant defense systems, thus alleviating high Cd toxicity [38]. Exogeneous $\mathrm{Mg}$ supply not only relieves symptoms of high $\mathrm{Cd}$-induced toxicity by altering the expression of
Cd-induced genes, but also inhibits $\mathrm{Cd}$ translocation from roots to shoots [39]. The concentrations of $\mathrm{Fe}^{2+}$, $\mathrm{Zn}^{2+}$, and $\mathrm{Cu}^{2+}$ were not significantly affected by low $\mathrm{Cd}$, however, their concentrations were significantly reduced in the shoots but were increased in the roots under high $\mathrm{Cd}$ (Fig. 1K-M). This result suggested that high $\mathrm{Cd}$ reduced the translocation of $\mathrm{Fe}^{2+}, \mathrm{Zn}^{2+}$, and $\mathrm{Cu}^{2+}$ from roots to shoots. Moderate $\mathrm{Fe}$ application eliminates $\mathrm{Cd}$-induced decrease in net photosynthetic rate as well as the disorder of antioxidant systems [40]. Foliar $\mathrm{Zn}$ application reduces root $\mathrm{Cd}$ translocation to shoots, while soil $\mathrm{Zn}$ application contributes to the reduction of root $\mathrm{Cd}$ concentrations [41]. Under both high $\mathrm{Cd}$ and low $\mathrm{Cd}$, only the concentrations of $\mathrm{Mn}^{2+}$ were remarkably changed in both shoots and roots (Fig. 1N), which implied close interactions occurred between $\mathrm{Cd}$ and $\mathrm{Mn}$. Although the $\mathrm{Mn}^{2+}$ uptake was significantly inhibited by both high $\mathrm{Cd}$ and low $\mathrm{Cd}$, both of which contributed to the translocation of $\mathrm{Mn}^{2+}$ from roots to shoots (Fig. 1N). Similarly, Mn supply significantly decreased $\mathrm{Cd}$ bioaccumulation in other plant species, including Celosia argentea, Phytolacca americana, and Lupinus albus [40, 42, 43]. The concentrations of $\mathrm{Na}^{+}$, functioning as a beneficial element under low concentrations for plants [44], were not significantly changed in both shoots and roots under low Cd (Fig. 1O). However, its concentration was significantly increased in the shoots but was decreased in the roots under high $\mathrm{Cd}$ (Fig. 1O), which suggested that high $\mathrm{Cd}$ favored the translocation of $\mathrm{Na}^{+}$from roots to shoots. $\mathrm{NaCl}$ addition in the $\mathrm{Cd}$-containing medium caused remarkable reductions in both $\mathrm{Cd}$ concentration and accumulation [3].

As a non-essential element, $\mathrm{Cd}$ may share a portion of the other metal transporters in plants [40], whereas specific $\mathrm{Cd}$ transporters have been not identified so far. The $\mathrm{Cd}$-induced inhibited uptake or translocation of other metal ions may be attributed to the antagonism [45]. The interaction between $\mathrm{Cd}$ and other metal ions could be used as guidance for the enhancement of plant $\mathrm{Cd}$ resistance and hyperaccumulation-based $\mathrm{Cd}$ phytoremediation in agricultural practice.

\section{Co-expression network assisted analysis of transcriptomic responses to high $\mathrm{cd}$ and low $\mathrm{cd}$ reveals core $\mathrm{cd}$ transporter genes}

Previous studies mainly focus on the responses of plants to high Cd toxicity [4], whereas heterogenous Cd conditions, including high phytotoxic $\mathrm{Cd}$ abundance and low Cd without obvious phytotoxicity, usually occur in soils [46]. In polyploid B. napus, multiple-copy gene families are common; therefore, identification of the core gene(s) is a key prerequisite for the understanding of molecular mechanisms underlying important agronomy traits. Therefore, systematic analysis of plant transcriptional 
responses to high $\mathrm{Cd}$ and low $\mathrm{Cd}$ and molecular characterization of $\mathrm{Cd}$ transporter genes will give us a comprehensive understanding of plant adaptation to heterogenous $\mathrm{Cd}$ conditions. The findings will provide elite gene resources for the genetic improvement of plant $\mathrm{Cd}$ resistance and hyperaccumulation-based $\mathrm{Cd}$ phytoremediation.

The result of principal component analysis revealed that the shoots and roots of rapeseed plants showed significantly distinct responses to high $\mathrm{Cd}$ and low $\mathrm{Cd}$ conditions (Fig. 2D). In this study, different $\mathrm{Cd}$ abundances exhibited significantly differential transcriptomic features in both shoots and roots of rapeseed plants (Fig. 2D), which indicated the abundances-dependent transcriptional responses of rapeseed to $\mathrm{Cd}$. Moreover, through principal component analysis (Fig. 2D), we proposed that the rapeseed tissues had a more pronounced effect on transcriptional features than the $\mathrm{Cd}$ abundances. In this study, more DEGs were identified in both shoots and roots of rapeseed plants under high $\mathrm{Cd}$ than those under low $\mathrm{Cd}$ (Fig. 2E-G), which suggested that high $\mathrm{Cd}$ had a more significant effect on the growth and molecular responses in B. napus than low $\mathrm{Cd}$.

Plant roots are the first organ that directly interacts with soil environmental stresses [47]. In the roots of rapeseed plants under low $\mathrm{Cd}$, the $\mathrm{GO}$ term involving response to external stimulus and the KEGG pathways involving MAPK signaling transduction were highly accumulated (Figs. 3C, 4C). Therefore, we presumed that low $\mathrm{Cd}$ triggered the defense response of rapeseed plants through activating MAPK signaling pathways (Fig. 1) although low $\mathrm{Cd}$ did not cause obvious leaf $\mathrm{Cd}$ toxicity (Fig. 1A). The overaccumulation of photosynthesisrelated KEGG terms under low $\mathrm{Cd}$ might be attributed to the fact that low $\mathrm{Cd}$ disturbed the homeostasis of $\mathrm{Mg}^{2+}$ and $\mathrm{Mn}^{2+}$ (Fig. 1J, N), both of which are key to photosynthesis [48]. Sulfur (S), an essential element for plants, participates in the metabolism of methionine, cysteine, glutathione, and phytochelatin [49]. Cell wall functions as an important physical barrier to protect plants from heavy metal contaminants by reducing uptake or preventing entry into the cytoplasm [50]. Meanwhile, cell wall is also a major site for $\mathrm{Cd}$ sequestration and accumulation [29]. Both GO and KEGG enrichment analysis showed that the metabolism of sulfide, including cysteine, methionine, and glutathione and phenylpropanoid biosynthesis, was the highly enriched group in the roots of rapeseed plants under high Cd (Figs. 3D, 4D), which highlighted that the pivotal roles of sulfurmediated chelation and cell wall-mediated retention in $\mathrm{Cd}$ hyperaccumulation and $\mathrm{Cd}$ resistance. In the shoots of rapeseed plants under low $\mathrm{Cd}$, the highly enriched GO and KEGG terms were mainly related to the biosynthesis of plant cell wall components (Figs. 3A, 4A). It enlightened us that regulation of cell wall metabolism might contribute to $\mathrm{Cd}$ hyperaccumulation in cell walls of plants, which is favorable for phytoremediation of $\mathrm{Cd}$ pollutants. However, in the shoots of rapeseed plants under high $\mathrm{Cd}$, the $\mathrm{GO}$ and KEGG terms involving photosynthesis, nitrogen transport and response, and response to ion homeostasis were over-accumulated (Figs. $3 \mathrm{~B}, 4 \mathrm{~B})$, which indicated that high $\mathrm{Cd}$ toxicity might mainly alter the expression of genes related to photosynthesis and nutrient metabolism.

The polyploidy events within the B. napus genome result in numerous duplicated segments and homoeologous regions, which cause formation of multi-copy gene families. Furthermore, the core $\mathrm{Cd}$ transporter genes within the rapeseed genome remain largely unknown, which greatly restricts the understanding of responsive mechanisms underlying strong $\mathrm{Cd}$ resistance and high $\mathrm{Cd}$ accumulation in rapeseed. In this study, based on gene functional annotation and co-expression networks, some core $\mathrm{Cd}$ transporter genes were identified, and these genes were presumed to main regulators responsible for $\mathrm{Cd}$ uptake and translocation. Therefore, integrated genomics and transcriptomics analysis might be an efficient pathway that was feasible for the rapid identification of core genes without performing genomewide association study or map-based gene cloning.

In this study, in terms of the NRAMPS mainly responsible for $\mathrm{Cd}$ uptake and transport, we found that BnaNRAMP5s had very low expression levels even under high $\mathrm{Cd}$, and did not identify the differential expression of BnaNRAMP5s under both high $\mathrm{Cd}$ and low Cd conditions (Fig. 5A). It indicated that NRAMP5s might not be involved in the $\mathrm{Cd}$ uptake and transport. Moreover, we found that some $\mathrm{Cd}$ transporters, such as BnaC7.NRAPM4, BnaC8.NRAPM3, and some BnaIRT1s, showed opposite expression patterns between high $\mathrm{Cd}$ and low Cd conditions (Figs. 5A, 6A).

In addition to impacting other metal homeostasis, we presumed that $\mathrm{Cd}$ also had a significant effect on metabolism of non-metal elements based on the transcriptome and RT-qPCR results. For example, the expression of nitrate and boron transporters was significantly changed, particularly under high $\mathrm{Cd}$ toxicity (Figs. 2A, 10A, G). In terms of nitrate transporters, NRT1.1/NPF6.3 is a dualaffinity nitrate influx transporter in the roots of plants [51], and NRT1.5/NPF7.3 is mainly responsible for root xylem nitrate loading [52]. In this study, both transcriptome and RT-qPCR results showed that the expression of BnaA9.NRT1.1 and BnaC5.NRT1.5 was repressed by high Cd toxicity (Fig. 2A). In Arabidopsis, it has been found that $\mathrm{Cd}$ inhibits nitrate uptake and inhibits the expression of NRT1.1, and loss of NRT1.1 function alleviates the phytotoxicity caused by $\mathrm{Cd}$ [53]. Increased nitrate is allocated to roots of the atnrt1.5 mutant, which 
shows stronger $\mathrm{Cd}$ resistance compared with the wide type [54]. Taken together, there may be a close interaction between nitrogen nutrients and $\mathrm{Cd}$ toxicity resistance. In addition, boron homeostasis might be also greatly affected by $\mathrm{Cd}$. In this study, the expression of a root boron influx channel NIP5;1 [55], induced by boron deficiency [56], was downregulated by high $\mathrm{Cd}$ toxicity (Fig. 10G), which suggested that Cd repressed the boron uptake. However, the expression of both a root xylem boron loading BOR1 [57] and a boron channel responsible for preferential transport of boron to growing shoot tissues, NIP6;1 [58], was significantly decreased under both high $\mathrm{Cd}$ and low $\mathrm{Cd}$ conditions (Figs. 2A, 10G). It suggested that $\mathrm{Cd}$ might inhibit the root xylem boron loading and boron recycling from source leaves to sinks. Previous studies show increased boron supply alleviates $\mathrm{Cd}$ toxicity through inhibiting $\mathrm{Cd}$ uptake and increasing cell wall-mediated $\mathrm{Cd}$ retention [59, 60]. Therefore, application of boron fertilizers could be used to reduce $\mathrm{Cd}$ accumulation and enhance $\mathrm{Cd}$ resistance.

This finding suggested that different strategies should be adopted through molecular modulation of Cd transporters for the genetic improvement of plant Cd resistance and phytoremediation under different $\mathrm{Cd}$ abundances. For example, enhancing the expression of BnaIRT1s might be favorable for hyperaccumulationbased $\mathrm{Cd}$ phytoremediation under low $\mathrm{Cd}$, whereas reducing the expression of BnaIRT1s might contribute to improving plant $\mathrm{Cd}$ resistance.

\section{Conclusions}

Taken together, in this study, we presented the differential genome-wide transcriptional responses of allotetraploid rapeseed $\left(A_{n} A_{n} C_{n} C_{n}\right)$ to varying $C d$ abundances, which greatly eased the identification of core Cd transporter gene members responsive to high $\mathrm{Cd}$ and low $\mathrm{Cd}$ based on the gene co-expression network analysis. Our findings will provide suitable gene resources and important implications for the genetic improvement of plant $\mathrm{Cd}$ accumulation and resistance through molecular engineering of these genes under varying $\mathrm{Cd}$ abundances in soils.

\section{Materials and methods}

\section{Plant materials and growth condition}

Considering the rapeseed cultivar of Zhongshuang 11 (a winter cultivar), having well-known information on genome sequences, is an elite genotype with high oil quality, seed production [61], and strong Cd resistance [30], we used Zhongshuang 11 as the rapeseed lines studied in the following experiments. Due to high homogeneity of culture media and easy management, hydroponic culture was used as the rapeseed-growing way, which is more suitable for this study than soil culture and tissue culture. B. napus seedlings, the seeds of which were collected from Prof. Jin-yong Huang (jinyhuang@zzu.edu. cn, Zhengzhou University, Zhengzhou, 450,001, China), were grown in an illuminated growth chamber using the Hoagland nutrient solution. Growth conditions were set as follows: light intensity of $150 \mu \mathrm{mol} \mathrm{m}^{-2} \mathrm{~s}^{-1}$, room temperature of $24^{\circ} \mathrm{C}$ daytime $/ 22^{\circ} \mathrm{C}$ night, light period of 16-h photoperiod/8-h dark, and relative humidity of $60 \%$ [62]. For the transcriptome sequencing, uniform rapeseed plants after 7-day seed germination were grown for $10 \mathrm{~d}$ under $\mathrm{Cd}$-free condition, and then the seedlings were transferred to the solution containing low $(0.50 \mu \mathrm{M})$ or high $(50 \mu \mathrm{M}) \mathrm{CdCl}_{2}$ for three days until sampling, when the rapeseed plants start to show slight $\mathrm{Cd}$ toxicity symptoms under high $\mathrm{Cd}$ condition.

\section{lonomic analysis}

For the ionomic analysis, uniform rapeseed plants after 7 -day seed germination were grown for $10 \mathrm{~d}$ under $\mathrm{Cd}$ free condition, and then the seedlings were transferred to the solution containing $0.50 \mu \mathrm{M}$ or $50 \mu \mathrm{M} \mathrm{CdCl} \mathrm{Cl}_{2}$ for five days until sampling, when the rapeseed plants start to show obvious $\mathrm{Cd}$ toxicity symptoms under high $\mathrm{Cd}$ condition. The shoot and root tissues of rapeseed plants were over-dried at $65^{\circ} \mathrm{C}$ to constant weight. Subsequently, the samples that were ground to fine powder were transferred to a $\mathrm{HNO}_{3} / \mathrm{HClO}_{4}$ mixture $(4: 1, \mathrm{v} / \mathrm{v})$ at $200^{\circ} \mathrm{C}$ until the digestion was completed. The diluted supernatant was submitted to an inductively coupled plasma mass spectrometry (ICP-MS; NexIONTM 350X, PerkinElmer) to quantify the concentrations of mineral elements [30]. Each sample contained five independent biological replicates.

\section{RNA extraction}

Total RNA was extracted from fresh rapeseed tissues using Invitrogen TRIzol ${ }^{\circ}$ Reagent (Thermo Fisher Scientific, California, USA) according to the manufacturer's instructions (Invitrogen), and genomic DNA was removed using DNase I (TaKara, Shiga, Japan). Then, RNA quality was determined by 2100 Bioanalyser (Agilent, Palo Alto, California, USA) and quantified using the NanoDrop 2000 (Thermo Fisher Scientific, Massachusetts, USA). Only high-quality RNA samples $\left(\mathrm{OD}_{260} /\right.$ $\mathrm{OD}_{280}=1.8 \sim 2.2, \quad \mathrm{OD}_{260} / \mathrm{OD}_{230} \geq 2.0, \quad \mathrm{RIN} \geq 6.5, \quad 28 \mathrm{~S}$ : $18 \mathrm{~S} \geq 1.0,>2.0 \mu \mathrm{g})$ were used to construct sequencing library.

\section{Library preparation and sequencing}

Transcriptome libraries were prepared following Tru$\mathrm{Seq}^{\text {TM }}$ RNA sample preparation Kit from Illumina (Illumina Inc., San Diego, California, USA) using $1.0 \mu \mathrm{g}$ of total RNA. Shortly, mRNA was isolated according to poly-A selection method by oligo(dT) beads, and was 
then fragmented by fragmentation buffer. Secondly, double-stranded cDNA was synthesized using a SuperScript double-stranded cDNA synthesis kit (Invitrogen, CA) with random hexamer primers (Illumina, San Diego, California, USA). Then, the synthesized cDNA was subjected to end-repair, phosphorylation, and ' $A$ ' base addition according to Illumina's library construction protocol. Libraries were size selected for cDNA target fragments of 200-300 bp on 2\% Low Range Ultra Agarose followed by PCR amplified using Phusion DNA polymerase (NEB) for 15 PCR cycles. After quantification by TBS380, paired-end RNA-seq sequencing library was sequenced with the Illumina HiSeq xten/NovaSeq 6000 sequencer $(2 \times 150 \mathrm{bp}$ read length).

\section{Read mapping}

The raw paired end reads were trimmed and quality controlled by SeqPrep (https://github.com/jstjohn/ SeqPrep) and Sickle (https://github.com/najoshi/sickle) with default parameters. Then, clean reads were separately aligned to reference genome with orientation mode using TopHat (http://tophat.cbcb.umd.edu/, version 2.0. $0)$ [63]. The mapping criterion of bowtie was as follows: sequencing reads should be uniquely matched to the genome allowing up to 2 mismatches, without insertions or deletions. Then the region of gene was expanded following depths of sites and the operon was obtained. In addition, the whole genome was split into multiple $15 \mathrm{~kb}$ windows that share $5 \mathrm{kbp}$. New transcribed regions were defined as more than two consecutive windows without overlapped region of gene, where at least 2 reads mapped per window in the same orientation.

Differential expression analysis and functional enrichment To identify differentially expressed genes (DEGs) between different treatments, the expression level of each transcript was calculated according to the fragmets per kilobase of exon per million mapped reads (FRKM) method. The DEGs were defined as those with a $P$ value and false discovery rate (FDR) that were less than 0.05 [64]. RSEM (http://deweylab.biostat.wisc.edu/rsem/) [65] was used to quantify gene expression abundances. $R$ statistical package software EdgeR (Empirical analysis of Digital Gene Expression in R, (http://www.bioconductor. org/packages/2.12/bioc/html/edgeR.html) [66] was utilized for differential expression-n analysis. The KaiserMeyer-Olkin test was used for perform principal component analysis, to determine how many components were necessary to reduce the high-dimensionality transcriptome expression data using $\mathrm{R}$ statistical package (https://www.r-project.org/).

In addition, functional-enrichment analysis, including GO and KEGG, was performed to identify which DEGs were significantly enriched in GO terms and metabolic pathways at Bonferroni-corrected $P$-value $\leq 0.05$ compared with the whole-transcriptome background. GO functional enrichment and KEGG pathway analysis were carried out by Goatools (https://github.com/tanghaibao/ Goatools) and KOBAS (http://kobas.cbi.pku.edu.cn/ home.do) [67].

\section{Gene co-expression network analysis}

The interaction relationships of each gene pair were calculated based on the corresponding transcript abundance (FPKM value) using the online DeGNServer (http://plantgrn.noble.org/DeGNServer/) [68]. The parameter settings were as follows: (i) value-based coexpression network type, (ii) Pearson correlation estimation method, and (iii) association cutoff $>0.6$. Gene coexpression networks were visualized by Cytoscape (http://www.cytoscape.org/) [69].

\section{Reverse transcription-quantitative polymerase chain reaction assays}

Reverse transcription-quantitative polymerase chain reaction (RT-qPCR) assays were performed to validate the accuracy of transcriptome sequencing data. After removing genomic DNA from RNA samples with RNase-free DNase I, total RNA was used as RT templates for cDNA synthesis using the PrimeScript ${ }^{\mathrm{tm}}$ RT Reagent Kit Eraser (Perfect Real Time; TaKaRa, Shiga, Japan). The RTqPCR assays were performed to detect relative gene expression using SYBR Premix Ex Taq ${ }^{\text {Th }}$ II (TliRNaseH Plus) (TaKaRa, Shiga, Japan) using a Bio-Rad C1000 touch Thermal Cycler of CFX96 ${ }^{\text {tw }}$ Real-time PCR detection System.

The RT-qPCR program was as follows: $95^{\circ} \mathrm{C}$ for 3 min, 40 cycles of $95^{\circ} \mathrm{C}$ for $10 \mathrm{~s}$, and $60^{\circ} \mathrm{C}$ for $30 \mathrm{~s}$. The melting curve was plotted as follows to analyze the primer gene-specificity: $95^{\circ} \mathrm{C}$ for $15 \mathrm{~s}, 60^{\circ} \mathrm{C}$ for $1 \mathrm{~min}$, and $60-95^{\circ} \mathrm{C}$ for $15 \mathrm{~s}\left(+0.3^{\circ} \mathrm{C} /\right.$ cycle). The expression data of target genes were normalized using two public internal reference genes, BnaEF1- $\alpha$ and BnaGDI1 [70], and the relative gene expression levels were calculated according to the $2^{-\Delta \Delta C}{ }_{T}$ method [71]. Each sample contained three independent biological replicates.

\section{Statistical analysis}

The Statistical Productions and Service Solutions 17.0 (SPSS, Chicago, IL, USA) was used to perform statistical tests. Student $t$ test or one-way variance of analysis, followed by Tukey's honestly significant difference multiple comparison tests, was used to determine the significance differences.

\section{Abbreviations}

ABC: ATP-binding cassette; CAX: cation exchanger; Cd: cadmium; DEG: differentially expressed genes; HMA: heavy metal ATPase; IRT: ironregulated transporter; MT: metallothionein; MTP: metal tolerance protein; 
NRAMP: natural resistance-associated macrophage proteins; PCR: plant cadmium resistance; PCS: phytochelatin synthetase; " YSL: yellow-stripe like; ZIP: ZRT/IRT-like protein

\section{Supplementary Information}

The online version contains supplementary material available at https://doi. org/10.1186/s12870-021-03136-w.

\section{Additional file 1.}

\section{Acknowledgements}

Not applicable.

\section{Authors' contributions}

YPH, TZ, CPY, and JYH initiated and designed the research. TYZ and YL performed the experiments. YPH and TZ analyzed the data. YPH and TZ wrote and revised the manuscript. CPY, and JYH supervised the project. All authors have read and approved the manuscript.

\section{Funding}

This study was financially supported by the National Natural Science Foundation of China (31801923 and U2004149), Major Collaborative Innovation Project of Zhengzhou City (Key Discipline Construction Project of Zhengzhou University) (NO. xkzdjc201905), Youth Innovation Project of Key discipline of Zhengzhou University (NO. XKZDQN202002), and Innovation Ecosystem Construction Science and Technology Special Project of National Supercomputing Zhengzhou Center (201400210600). The funder was not involved in the experimental design of the study, data collection, analysis and interpretation, and in writing the manuscript.

\section{Availability of data and materials}

All the data and materials that are required to reproduce these findings can be shared by contacting the corresponding author, Dr. Ying-peng Hua (yingpenghua@zzu.edu.cn).

\section{Declarations}

Ethics approval and consent to participate

In this study, all the seeds of rapeseed plants were obtained from our research group led by Prof. Jin-yong Huang (jinyhuang@zzu.edu.cn, Zhengzhou University, Zhengzhou, 450001, Henan Province, China).

\section{Consent for publication}

Not applicable.

\section{Competing interests}

The authors declare that they have no conflict of interest.

Received: 26 March 2021 Accepted: 25 July 2021

Published online: 13 August 2021

\section{References}

1. Zhang $X$, Li X, Tang L, Peng Y, Qian M, Guo $Y$, et al. The root iron transporter 1 governs cadmium uptake in Vicia sativa roots. J Hazard Mater. 2020:398:122873.

2. Genchi G, Sinicropi MS, Lauria G, Carocci A, Catalano A. The effects of cadmium toxicity. Int J Env Res Pub He. 2020;17:3782.

3. Huang YZ, Wei K, Yang J, Dai F, Zhang GP. Interaction of salinity and cadmium stresses on mineral nutrients, sodium, and cadmium accumulation in four barley genotypes. J Zhejiang Univ Sci B. 2007:8:47685

4. Raza A, Habib M, Kakavand SN, Zahid Z, Zahra N, Sharif R, Hasanuzzaman M. Phytoremediation of cadmium: physiological, biochemical, and molecular mechanisms. Biology (Basel). 2020;9:E177.

5. Uraguchi S, Kamiya T, Sakamoto T, Kasai K, Sato Y, Nagamura Y, et al. Lowaffinity cation transporter (OsLCT1) regulates cadmium transport into rice grains. Proc Natl Acad Sci U S A. 2011;108:20959-64.
6. Sasaki A, Yamaji N, Yokosho K, Ma JF. Nramp5 is a major transporter responsible for manganese and cadmium uptake in rice. Plant Cell. 2012;24: 2155-67.

7. Chang JD, Huang S, Konishi N, Wang P, Chen J, Huang XY, et al. Overexpression of the manganese/cadmium transporter OsNRAMP5 reduces cadmium accumulation in rice grain. J Exp Bot. 2020;71:5705-15.

8. Feng S, Tan J, Zhang Y, Liang S, Xiang S, Wang H, et al. Isolation and characterization of a novel cadmium-regulated yellow stripe-like transporter (SnYSL3) in Solanum nigrum. Plant Cell Rep. 2017;36:281-96.

9. Nakanishi H, Ogawa I, Ishimaru Y, Mori S, Nishizawa NK. Iron deficiency enhances cadmium uptake and translocation mediated by the $\mathrm{Fe}^{2+}$ transporters OsIRT1 and OsIRT2 in rice. Soil Sci Plant Nutri. 2006;52:464-9.

10. Takahashi $R$, Ishimaru, $Y$, Senoura $T$, Shimo H, Ishikawa $S$, Arao T, Nakanishi $H$, Nishizawa NK. The OsNRAMP1 iron transporter is involved in cd accumulation in rice. J Exp Bot 2011:62:4843-4850.

11. Ueno D, Yamaji N, Kono I, Huang CF, Ando T, Yano M, et al. Gene limiting cadmium accumulation in rice. Proc Natl Acad Sci U S A. 2010;107:16500-5.

12. Takahashi R, Ishimaru $Y$, Shimo H, Ogo Y, Senoura T, Nishizawa NK, et al. The OsHMA2 transporter is involved in root-to-shoot translocation of $\mathrm{Zn}$ and $\mathrm{cd}$ in rice. Plant Cell Environ. 2012;35:1948-57.

13. Zhang M, Zhang J, Lu L, Zhu Z, Yang X. Functional analysis of CAX2-like transporters isolated from two ecotypes of Sedum alfredii. Biol Plant. 2016; 60:37-47.

14. Filiz E, Saracoglu IA, Ozyigit II, Yalcin B. Comparative analyses of phytochelatin synthase (PCS) genes in higher plants. Biotechnol Biotec Eq. 2019;33:178-94.

15. Brunetti P, Zanella L, De Paolis A, Di Litta D, Cecchetti V, Falasca G, et al. Cadmium-inducible expression of the ABC-type transporter AtABCC3 increases phytochelatin-mediated cadmium tolerance in Arabidopsis. J Exp Bot 2015:66:3815-29.

16. Park J, Song WY, Ko D, Eom Y, Hansen TH, Schiller M, et al. The phytochelatin transporters AtABCC1 and AtABCC2 mediate tolerance to cadmium and mercury. Plant J. 2012;69:278-88.

17. Fu S, Lu Y, Zhang X, Yang G, Chao D, Wang Z, et al. The ABC transporter ABCG36 is required for cadmium tolerance in rice. J Exp Bot. 2019;70:5909-18.

18. Song WY, Choi KS, Kim DY, Geisler M, Park J, Vincenzetti $V$, et al. Arabidopsis PCR2 is a zinc exporter involved in both zinc extrusion and long-distance zinc transport. Plant Cell. 2010:22:2237-52.

19. Migocka M, Papierniak A, Kosieradzka A, Posyniak E, Maciaszczyk-Dziubinska E, Biskup R, et al. Cucumber metal tolerance protein CsMTP9 is a plasma membrane $\mathrm{H}^{+}$-coupled antiporter involved in the $\mathrm{Mn}^{2+}$ and $\mathrm{Cd}^{2+}$ efflux from root cells. Plant J. 2015;84:1045-58.

20. Ding S, Ma C, Shi W, Liu W, Lu Y, Liu Q, et al. Exogenous glutathione enhances cadmium accumulation and alleviates its toxicity in Populus $X$ canescens. Tree Physiol. 2017;37:1697-712.

21. He J, Zhuang $X$, Zhou J, Sun L, Wan H, Li H, et al. Exogenous melatonin alleviates cadmium uptake and toxicity in apple rootstocks. Tree Physiol. 2020;40:746-61

22. Verbruggen $\mathrm{N}$, Hermans $\mathrm{C}$, Schat $\mathrm{H}$. Molecular mechanisms of metal hyperaccumulation in plants. New Phytol. 2009;181:759-76.

23. Peng JS, Wang YJ, Ding G, Ma HL, Zhang YJ, Gong JM. A pivotal role of cell wall in cadmium accumulation in the crassulaceae hyperaccumulator Sedum plumbizincicola. Mol Plant. 2017:10:771-4

24. Manciulea A, Ramsey MH. Effect of scale of cd heterogeneity and timing of exposure on the cd uptake and shoot biomass, of plants with a contrasting root morphology. Sci Total Environ. 2006;367:958-67.

25. Lei GJ, Fujii-Kashino M, Wu DZ, Hisano H, Saisho D, Deng FL, Yamaji N, Sato K, Zhao FJ, Ma JF. Breeding for low cadmium barley by introgression of a Sukkula-like transposable element. Nat Food 2020. 2020;1:489-99.

26. Chalhoub B, Denoeud F, Liu S, Parkin IA, Tang H, Wang X, et al. Early allopolyploid evolution in the post-Neolithic Brassica napus oilseed genome. Science. 2014:345:950-3.

27. Grispen VM, Nelissen HJ, Verkleij JA. Phytoextraction with Brassica napus L.: a tool for sustainable management of heavy metal contaminated soils. Environ Pollut. 2006;144:77-83

28. Lacalle RG, Gómez-Sagasti MT, Artetxe U, Garbisu C, Becerril JM. Brassica napus has a key role in the recovery of the health of soils contaminated with metals and diesel by rhizoremediation. Sci Total Environ. 2018:618:347-56.

29. Wu X, Song H, Guan C, Zhang Z. Boron alleviates cadmium toxicity in Brassica napus by promoting the chelation of cadmium onto the root cell wall components. Sci Total Environ. 2020;728:138833. 
30. Zhang ZH, Zhou T, Tang TJ, Song HX, Guan CY, Huang JY, et al. A multiomics approach reveals the pivotal role of subcellular reallocation in determining rapeseed resistance to cadmium toxicity. J Exp Bot. 2019;70: 5437-55.

31. Zhang XD, Zhao KX, Yang ZM. Identification of genomic ATP binding cassette $(A B C)$ transporter genes and cd-responsive $A B C$ in Brassica napus. Gene. 2018:664:139-51.

32. Zhang XD, Meng JG, Zhao KX, Chen X, Yang ZM. Annotation and characterization of cd-responsive metal transporter genes in rapeseed (Brassica napus). BioMetals. 2017;31:107-21.

33. Robinson NJ, Tommey AM, Kuske C, Jackson PJ. Plant metallothioneins. Biochem J. 1993;295:1-10.

34. Leszczyszyn OI, Imam HT, Blindauer CA. Diversity and distribution of plant metallothioneins: a review of structure, properties and functions. Metallomics. 2013:5:1146-69.

35. Song $Y$, Wang $Y$, Mao $W$, Sui $H$, Yong L, Yang D, et al. Dietary cadmium exposure assessment among the Chinese population. PLoS One. 2017;12: e0177978.

36. de Anicésio ÉCA, Monteiro FA. Potassium affects the phytoextraction potential of Tanzania guinea grass under cadmium stress. Environ Sci Pollut Res Int. 2019:26:30472-84.

37. Wu Q, Zhu X, Zhao X, Shen R. Potassium affects cadmium resistance in Arabidopsis through facilitating root cell wall $c d$ retention in a nitric oxide dependent manner. Environ Exp Bot. 2020;178.

38. Nouairi I, Jalali K, Essid S, Zribi K, Mhadhbi H. Alleviation of cadmiuminduced genotoxicity and cytotoxicity by calcium chloride in faba bean (Vicia faba L. var. minor) roots. Physiol Mol Biol Plants. 2019;25:921-31.

39. Kudo H, Kudo K, Uemura M, Kawai S. Magnesium inhibits cadmium translocation from roots to shoots, rather than the uptake from roots, in barley. Botany. 2015;93:345-51.

40. Liu J, Yu G, Jiang PP, Zhang XF, Meng DJ, Chen Z, et al. Interaction of Mn and $\mathrm{cd}$ during their uptake in Celosia argentea differs between hydroponic and soil systems. Plant Soil. 2020;450:323-36.

41. Zhou J, Zhang C, Du B, Cui H, Fan X, Zhou D, et al. Effects of zinc application on cadmium (cd) accumulation and plant growth through modulation of the antioxidant system and translocation of cd in low- and high-cd wheat cultivars. Environ Pollut. 2020;265:115045.

42. Peng K, Luo C, You W, Lian C, Li X, Shen Z. Manganese uptake and interactions with cadmium in the hyperaccumulator Phytolacca americana L. J Hazard Mater. 2008;154:674-81.

43. Zornoza P, Sánchez-Pardo B, Carpena RO. Interaction and accumulation of manganese and cadmium in the manganese accumulator Lupinus albus. J Plant Physiol. 2010;167:1027-32.

44. Raddatz N, Morales de Los Ríos L, Lindahl M, Quintero FJ, Pardo JM. Coordinated transport of nitrate, potassium, and sodium. Front Plant Sci. 2020;11:247.

45. Liu H, Zhang Y, Chai T, Tan J, Wang J, Feng S, et al. Manganese-mitigation of cadmium toxicity to seedling growth of Phytolacca acinosa Roxb. Is controlled by the manganese/cadmium molar ratio under hydroponic conditions. Plant Physiol Bioch. 2013;73:144-53.

46. Haider FU, Liqun C, Coulter JA, Cheema SA, Wu J, Zhang R, et al. Cadmium toxicity in plants: impacts and remediation strategies. Ecotoxicol Environ Saf. 2021;211:111887

47. Leng Y, Li Y, Wen Y, Zhao H, Wang Q, Li SW. Transcriptome analysis provides molecular evidences for growth and adaptation of plant roots in cadimiumcontaminated environments. Ecotoxicol Environ Saf. 2020;204:111098.

48. Edwards GE, Andreo CS. NADP-malic enzyme from plants. Phytochemistry. 1992:31:1845-57.

49. Li Q, Gao Y, Yang A. Sulfur homeostasis in plants. Int J Mol Sci. 2020;21.

50. Conn S, Gilliham M. Comparative physiology of elemental distributions in plants. Ann Bot. 2010;105:1081-02.

51. $\mathrm{Ho} \mathrm{CH}$, Lin $\mathrm{SH}, \mathrm{Hu} \mathrm{HC}$, Tsay YF. CHL1 functions as a nitrate sensor in plants. Cell. 2009;138:1184-94.

52. Lin SH, Kuo HF, Canivenc G, Lin CS, Lepetit M, Hsu PK, et al. Mutation of the Arabidopsis NRT1.5 nitrate transporter causes defective root-to-shoot nitrate transport. Plant Cell. 2008;20:2514-28.

53. Mao QQ, Guan MY, Lu KX, Du ST, Fan SK, Ye YQ, Lin XY, Jin CW. Inhibition of nitrate transporter 1.1-controlled nitrate uptake reduces cadmium uptake in Arabidopsis. Plant Physiol. 2014;166:934-44.

54. Chen CZ, LV XF, Li JY, Yi HY, Gong JM. Arabidopsis NRT1.5 is another essential component in the regulation of nitrate reallocation and stress tolerance. Plant Physiol. 2014;159:1582-90.
55. Takano J, Wada M, Ludewig U, Schaaf G, von Wirén N, Fujiwara T. The Arabidopsis major intrinsic protein NIP5;1 is essential for efficient boron uptake and plant development under boron limitation. Plant Cell. 2006;18: 1498-509.

56. Hua Y, Zhang D, Zhou T, He M, Ding G, Shi L, et al. Transcriptomics-assisted quantitative trait locus fine mapping for the rapid identification of a nodulin 26-like intrinsic protein gene regulating boron efficiency in allotetraploid rapeseed. Plant Cell Environ. 2016;39:1601-18.

57. Takano J, Noguchi K, Yasumori M, Kobayashi M, Gajdos Z, Miwa K, et al. Arabidopsis boron transporter for xylem loading. Nature. 2002;420:337-40.

58. Tanaka M, Wallace IS, Takano J, Roberts DM, Fujiwara T. NIP6;1 is a boric acid channel for preferential transport of boron to growing shoot tissues in Arabidopsis. Plant Cell. 2008;20:2860-75.

59. Qin S, Liu H, Rengel Z, Gao W, Nie Z, Li C, et al. Boron inhibits cadmium uptake in wheat (Triticum aestivum) by regulating gene expression. Plant Sci. 2020;297:110522

60. Riaz M, Kamran M, Fang Y, Yang G, Rizwan M, Ali S, et al. Boron supply alleviates cadmium toxicity in rice (Oryza sativa L.) by enhancing cadmium adsorption on cell wall and triggering antioxidant defense system in roots. Chemosphere. 2021;266:128938.

61. Sun F, Fan G, Hu Q, Zhou Y, Guan M, Tong C, et al. The high-quality genome of Brassica napus cultivar 'ZS11' reveals the introgression history in semi-winter morphotype. Plant J. 2017;92:452-68.

62. Zhang ZH, Zhou T, Liao Q, Yao JY, Liang GH, Song HX, et al. Integrated physiologic, genomic and transcriptomic strategies involving the adaptation of allotetraploid rapeseed to nitrogen limitation. BMC Plant Biol. 2018;18: 322.

63. Trapnell C, Pachter L, Salzberg SL. TopHat: discovering splice junctions with RNA-Seq. Bioinformatics. 2009;25:1105-11.

64. Secco D, Jabnoune M, Walker $H$, Shou H, Wu P, Poirier $Y$, et al. Spatiotemporal transcript profiling of rice roots and shoots in response to phosphate starvation and recovery. Plant Cell. 2013;25:4285-304.

65. Li B, Dewey CN. RSEM: accurate transcript quantification from RNA-Seq data with or without a reference genome. BMC Bioinformatics. 2011;12:323.

66. Robinson MD, McCarthy DJ, Smyth GK. edgeR: a bioconductor package for differential expression analysis of digital gene expression data. Bioinformatics. 2010;26:139-40.

67. Xie C, Mao X, Huang J, Ding Y, Wu J, Dong S, Kong L, Gao G, Li CY, Wei L. KOBAS 2.0: a web server for annotation and identification of enriched pathways and diseases. Nucleic Acids Res. 2011;39:W316-22.

68. Saito R, Smoot ME, Ono K, Ruscheinski J, Wang PL, Lotia S, et al. A travel guide to Cytoscape plugins. Nat Methods. 2012;9:1069-76.

69. Kohl M, Wiese S, Warscheid B. Cytoscape: software for visualization and analysis of biological networks. Methods Mol Biol. 2011;696:291-303.

70. Maillard A, Etienne P, Diquélou S, Trouverie J, Billard V, Yvin JC, et al. Nutrient deficiencies in Brassica napus modify the ionomic composition of plant tissues: a focus on cross-talk between molybdenum and other nutrients. J Exp Bot. 2016:67:5631-41.

71. Livak KJ, Schmittgen TD. Analysis of relative gene expression data using real-time quantitative PCR and the $2^{-\Delta \Delta C}$ method. Methods. 2001;25:402-8.

\section{Publisher's Note}

Springer Nature remains neutral with regard to jurisdictional claims in published maps and institutional affiliations.

Ready to submit your research? Choose BMC and benefit from:

- fast, convenient online submission

- thorough peer review by experienced researchers in your field

- rapid publication on acceptance

- support for research data, including large and complex data types

- gold Open Access which fosters wider collaboration and increased citations

- maximum visibility for your research: over $100 \mathrm{M}$ website views per year

At $\mathrm{BMC}$, research is always in progress.

Learn more biomedcentral.com/submission 